\title{
Selective Ablation of Pillar and Deiters' Cells Severely Affects Cochlear Postnatal Development and Hearing in Mice
}

\author{
Marcia M. Mellado Lagarde, ${ }^{1,2}$ Brandon C. Cox,${ }^{1}$ Jie Fang, ${ }^{1}$ Ruth Taylor, ${ }^{3}$ Andrew Forge, ${ }^{3}$ and Jian Zuo ${ }^{1}$ \\ ${ }^{1}$ Department of Developmental Neurobiology, St. Jude Children's Research Hospital, Memphis, Tennessee 38103, ${ }^{2}$ School of Pharmacy and Biomolecular \\ Sciences, University of Brighton, Brighton BN2 4GJ, United Kingdom, and ${ }^{3}$ Ear Institute, University College London, London WC1X 8EE, United Kingdom
}

\begin{abstract}
Mammalian auditory hair cells (HCs) are inserted into a well structured environment of supporting cells (SCs) and acellular matrices. It has been proposed that when HCs are irreversibly damaged by noise or ototoxic drugs, surrounding SCs seal the epithelial surface and likely extend the survival of auditory neurons. Because SCs are more resistant to damage than HCs, the effects of primary SC loss on HC survival and hearing have received little attention. We used the Cre/loxP system in mice to specifically ablate pillar cells (PCs) and Deiters' cells (DCs). In Prox1CreER ${ }^{\mathrm{T} 2}+/-;$ Rosa26 $^{\mathrm{DTA} /+}$ (Prox1DTA) mice, Cre-estrogen receptor (CreER) expression is driven by the endogenous Proxl promoter and, in presence of tamoxifen, removes a stop codon in the Rosa26 ${ }^{\mathrm{DTA} /+}$ allele and induces diphtheria toxin fragment A (DTA) expression. DTA produces cell-autonomous apoptosis. Prox1DTA mice injected with tamoxifen at postnatal days 0 (P0) and P1 show significant DC and outer PC loss at P2-P4, that reaches $\sim 70 \%$ by 1 month. Outer HC loss follows at P14 and is almost complete at 1 month, while inner HCs remain intact. Neural innervation to the outer HCs is disrupted in Prox1DTA mice and auditory brainstem response thresholds in adults are 40-50 dB higher than in controls. The hearing deficit correlates with loss of cochlear amplification. Remarkably, in Prox1DTA mice, the auditory epithelium preserves the ability to seal the reticular lamina and spiral ganglion neuron counts are normal, a key requirement for cochlear implant success. In addition, our results show that cochlear SC pools should be appropriately replenished during $\mathrm{HC}$ regeneration strategies.
\end{abstract}

\section{Introduction}

The organ of Corti, the auditory sensory organ in mammals, is a highly specialized epithelium in structure (Fig. $1 \mathrm{~A}$ ) and function. Among its unique properties are electromotile outer hair cells (HCs) (Brownell, 1990), stiff supporting cells (SCs) (Tolomeo and Holley, 1997), and gradients of mechanical and electrical properties along its spiral shape. These and other characteristics are responsible for the organ's high sensitivity, fine frequency analysis, and wide dynamic range when responding to incoming sounds.

Received June 28, 2012; revised Nov. 29, 2012; accepted Nov. 30, 2012.

Author contributions: M.M.M.L., B.C.C., and J.Z. designed research; M.M.M.L. performed research; J.F. contributed unpublished reagents/analytic tools; M.M.M.L., R.T., and A.F. analyzed data; M.M.M.L., B.C.C., J.F., R.T., A.F., and J.Z. wrote the paper.

This article is freely available online through the J Neurosci Open Choice option.

This work was supported by the Wellcome Trust and grants from the National Institutes of Health (DC006471, DC008800, and CA21765 to J.Z.; DC010310 to B.C.C.), the Office of Naval Research (N000140911014, N000141210775, and N000141210191 to J.Z.), and the American Lebanese Syrian Associated Charities of St. Jude Children's Research Hospital. M.M.M.L. is a recipient of a Sir Henry Wellcome Fellowship (089015). J.Z. is a recipient of The Hartwell Individual Biomedical Research Award. J.F. is a recipient of a research award from the National Organization for Hearing Research Foundation. We thank L. Zhang (St. Jude) for mouse genotyping; G. Oliver (St. Jude) for the Prox1CreER ${ }^{\mathrm{T} 2}$ mice; A. Lavado (St. Jude) for constructive discussion; K. Steigelman (St. Jude), S. Frase (St. Jude), the members of the St. Jude electron-microscopy facility, and L. Boykins (University of Memphis) for assistance with electron microscopy; the St. Jude imaging facility members for their help with confocal microscopy; J. Dearman (St. Jude) for animal care and equipment maintenance; Z. Liu (St. Jude) for constructive discussion; I. Russell (University of Brighton) for critical comments on the manuscript; A. Lenoir (St. Jude) for initial collection of samples; and B. Williford (St. Jude) for work on the cochlear scheme.

The authors declare no competing financial interests.

Correspondence should be addressed to Jian Zuo, St. Jude Children's Research Hospital, 262 Danny Thomas Place, Memphis, TN 38105. E-mail: Jian.Zuo@stjude.org.

DOI:10.1523/JNEUROSCI.3088-12.2013

Copyright $\odot 2013$ the authors $\quad 0270-6474 / 13 / 331564-13 \$ 15.00 / 0$
$\mathrm{HC}$ loss is irreversible in mammals and is the primary cause of hearing impairment in humans. Many studies have investigated $\mathrm{HC}$ function and the consequences of HC damage induced by noise and ototoxic drugs. Much less is known about the roles of the SCs that lie in close contact with the HCs and largely determine the mature structure of the organ of Corti.

Interestingly, during postnatal development, cochlear SCs change their morphology in parallel with important HC differentiation steps. Specifically, pillar cells (PCs) and Deiters' cells (DCs) develop and open spaces around the HCs (the tunnel of Corti and the spaces of Nuel) at the time of onset of outer HC electromotility (He et al., 1994; Souter et al., 1997). PCs and DCs have slanting, stiff bodies that connect outer HCs along the cochlear spiral and likely play a role in frequency tuning (Geisler and Sang, 1995; Russell and Nilsen, 1997; Tolomeo and Holley, 1997). Additionally, researchers have found that after HC damage, SCs seal the reticular lamina (McDowell et al., 1989; Raphael and Altschuler, 1991a,b), a key step in maintaining separation between the endolymph and the perilymph. SCs also help eliminate HC debris (Abrashkin et al., 2006; Bird et al., 2010). Furthermore, survival of spiral ganglion neurons after HC damage has been correlated with presence of cochlear SCs (Stankovic et al., 2004; Zilberstein et al., 2012). Finally, strategies to achieve HC regeneration in mammals target SCs, since they replenish lost HCs in nonmammalian vertebrates (Corwin and Cotanche, 1988; Ryals and Rubel, 1988; Warchol, 2011).

The aim of this study is to determine the roles of specific SCs in cochlear development and hearing capabilities. For the first time, we achieved SC ablation as a cell-specific, primary event in the 
A

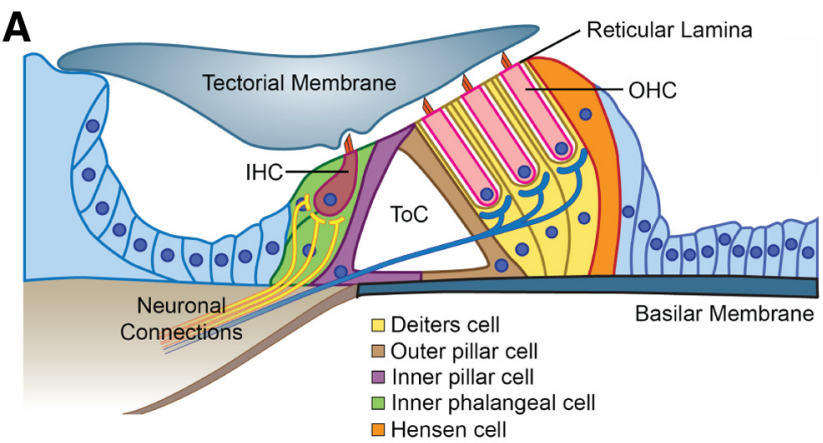

B
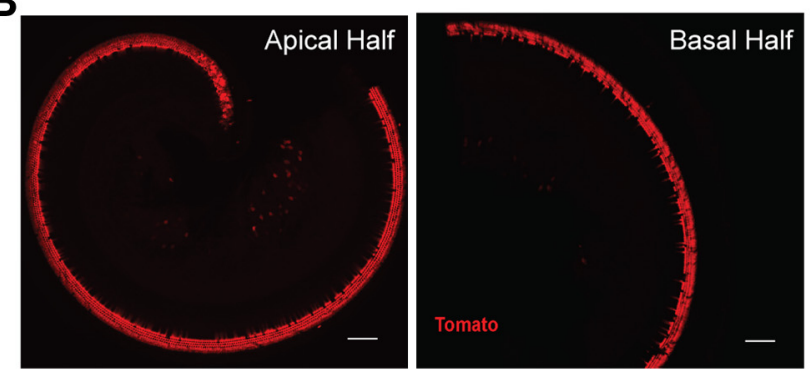

CP7
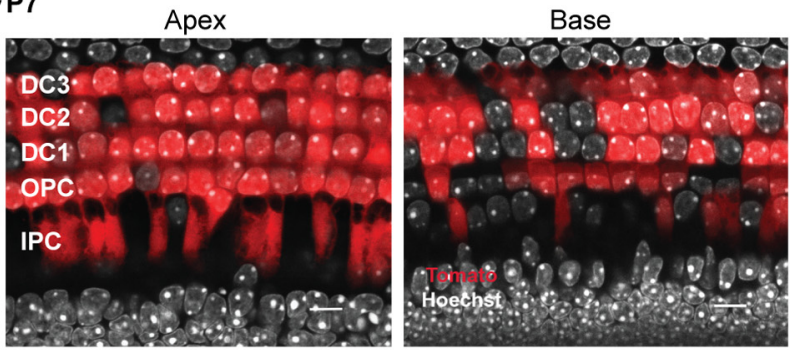

D

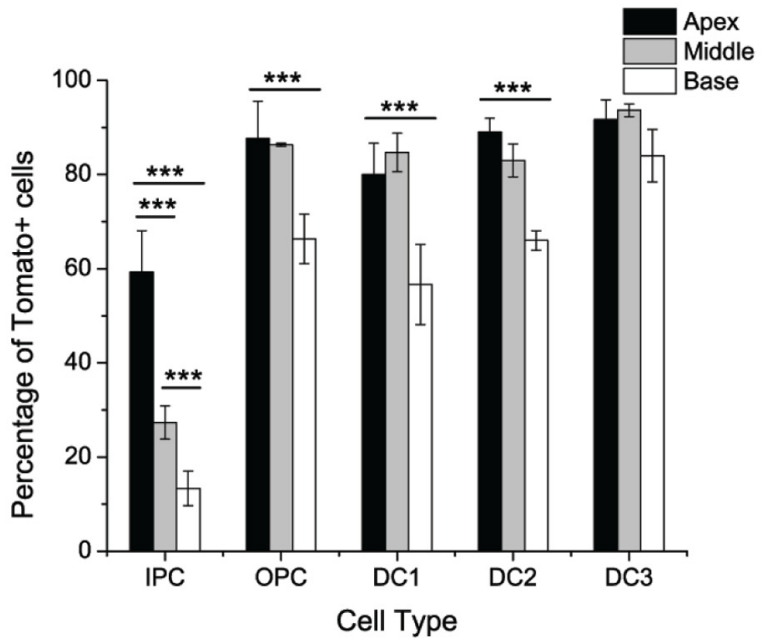

Figure 1. Prox1CreER ${ }^{\mathrm{T} 2}$ expression pattern in the organ of Corti revealed by the Ai14 (Rosa26-CAG-loxP-stop-loxP-tdTomato) reporter. A, Scheme of a cochlear cross section showing the relative position of $\mathrm{HCs}$ and $\mathrm{SC} s$ within the organ of Corti. The wild-type, mature organ of Corti has one row of inner $\mathrm{HCS}(\mathrm{IHC})$ and three rows of outer $\mathrm{HCS}(\mathrm{OHC})$ separated by one row of inner $P C s$ and one row of outer $P(s$ that form the tunnel of Corti (ToC). Deiters' cells connect the $\mathrm{OHCs}$ to the basilar membrane and extend phalanges to the reticular lamina reaching $2-30 \mathrm{HCS}$ away and leaving spaces around them (spaces of Nuel). Inner phalangeal cells surround the inner HCs. Hensen cells contact DCs at the lateral edge of the organ of Corti. Cell nuclei are depicted as blue circles and show that $P C$ and $D C$ nuclei are beneath $H C$ nuclei. $\boldsymbol{B}$, Representative optical sections taken at low magnification from the apical and basal halves of a Prox1Ai14 cochlea at P7 showing Tomato (red) expression in cochlear SCs along the turn. Scale bars, 100 $\mu \mathrm{m}$. C, Representative optical sections of apical and basal regions of the cochleae of Prox1Ai14 mice at P7 using a higher magnification showing Tomato $+P C s$ and DCs. Scale bars, $10 \mu \mathrm{m}$. D, Quantification of Tomato + SCs as a percentage of the total number of cells for each specific organ of Corti and found significant impact on auditory development and function. We targeted PCs and DCs because they are in direct contact with inner and outer HCs and show the most conspicuous morphology in the organ of Corti. We used Prox $1 \mathrm{CreER}^{\mathrm{T} 2}+/-{\text { Rosa } 26^{\mathrm{DTA} /+}}$ mice, in which PCs and DCs die via apoptosis. We extended the characterization of ProxiCreER ${ }^{\mathrm{T} 2}$ expression in the cochlea using the highefficiency Ai14 reporter.

Our data show that significant PC and DC death disrupts cochlear architecture and produces outer HC loss. However, despite the suggested role of these cells in scar formation, the reticular lamina remains sealed. Severe hearing loss in Prox1DTA mice correlates with outer $\mathrm{HC}$ loss, while primary neuron survival is independent of degeneration of the cochlear epithelium.

\section{Materials and Methods}

Mouse models. Prox1CreER ${ }^{\mathrm{T} 2}$ knockin mice (Srinivasan et al., 2007) were kindly provided by Dr. G. Oliver at St. Jude Children's Research Hospital. Genotyping and tamoxifen induction [once a day at postnatal day 0 (P0) and $\mathrm{P} 1,0.075 \mathrm{mg} / \mathrm{g}$ bodyweight, i.p.] protocols have been previously described (Srinivasan et al., 2007; Yu et al., 2010). Ail4 mice were obtained from The Jackson Laboratory (stock \#007908). Ai14 mice have a CAG promoter-driven red fluorescent protein variant (tdTomato, called here Tomato), which is expressed after removal of a loxP-flanked stop cassette knocked in the Rosa26 locus and serves as a high-efficiency reporter of Cre activity (Madisen et al., 2010). Ail4 mice were bred with Prox $1 C r e E R^{\mathrm{T} 2}$ mice and littermates of either sex were used for experiments. Rosa26 ${ }^{\text {DTA }}$ transgenic mice (Ivanova et al., 2005) were purchased from The Jackson Laboratory (stock \#006331) and genotyped using primers recognizing the diphtheria toxin fragment A (DTA) sequence (5'TGACGATGATTGGAAAGGGT3' and 5'TGAGCACTACACGCGA AGCA3'), which generated a 300 bp band showing presence of the DTA allele. Prox1CreER ${ }^{\mathrm{T} 2}+/-;$ Rosa26 $^{\mathrm{DTA} /+}$ (Prox1DTA) mice of either sex, induced with tamoxifen at $\mathrm{P} 0$ and $\mathrm{P} 1$, were studied at ages between $\mathrm{P} 2$ and 8 weeks and compared with control mice of either sex. Littermates with only one of the alleles (i.e., Prox $1 \mathrm{CreER}^{\mathrm{T} 2}+/-$ and Rosa $26^{\mathrm{DTA} /+}$ ) were used as controls and induced with tamoxifen identically to Prox1DTA mice. We also used control mice that were Prox 1 CreER ${ }^{\mathrm{T} 2}+/-$; Rosa26 $6^{\mathrm{DTA} /+}$ not induced with tamoxifen. PrestinCreER ${ }^{\mathrm{T} 2}$ knockin mice, previously generated in our laboratory (Fang et al., 2012), were bred with Rosa $26^{\text {DTA/+ }}$ mice and littermates of either sex were used for experiments. Genotyping and tamoxifen induction (once a day at P21 and P22, $0.225 \mathrm{mg} / \mathrm{g}$ bodyweight, i.p.) protocols have been previously described (Fang et al., 2012). Controls for experimental PrestinCreER ${ }^{\mathrm{T} 2}+/-;$ Rosa26 $^{\mathrm{DTA} /+}$ (PrestinDTA) mice were littermates with only one of the alleles (i.e., PrestinCreER ${ }^{\mathrm{T} 2}+/-$ and Rosa $26^{\mathrm{DTA} /+}$ ) induced with tamoxifen following the same protocol. Animal procedures were all approved by the Institutional Animal Care and Use Committee of St. Jude Children's Research Hospital.

Immunohistochemistry. Inner ears were dissected out of the temporal bone and fixed in $4 \%$ paraformaldehyde in $10 \mathrm{~mm}$ phosphate buffer (PBS), pH 7.4, overnight at room temperature. Inner ears from mice P8 or older were decalcified with $120 \mathrm{~mm}$ EDTA in $10 \mathrm{~mm}$ PBS, pH 7.4, at $4^{\circ} \mathrm{C}$. For whole mounts, cochleae were dissected and divided into two (apex, base) or three pieces (apical, middle, base). For cryosections, cochleae were incubated in $30 \%$ sucrose overnight at $4^{\circ} \mathrm{C}$, embedded in Tissue Freezing Medium (Triangle Biomedical Sciences) and frozen at $-80^{\circ} \mathrm{C}$. Sections of $12 \mu \mathrm{m}$ were cut using a Cryostat Leica CM3050.

Sections and whole mounts were washed with $10 \mathrm{~mm}$ PBS and blocked with $1 \%$ bovine serum albumin (BSA), $10 \%$ goat or horse serum, and $1 \%$

type. Statistical differences in the percentage of cells labeled between turns were determined by a two-way ANOVA followed by Student's $t$ test with Bonferroni correction $\left({ }^{* * *} p<0.001\right.$, $N=3$ ). There are no significant differences in the percentages of labeled cells between apex and middle for outer $\mathrm{PC}$ and $\mathrm{DC}$. IPC, inner $\mathrm{PC} ; \mathrm{OPC}$, outer $\mathrm{PC} ; \mathrm{DC} 1-3$, Deiters' cells from rows $1-3$ with row 1 being the closest to the inner HCs. 
Triton X-100 in PBS for $1 \mathrm{~h}$ at room temperature. Primary antibodies were diluted in $1 \%$ BSA, $5 \%$ goat or horse serum, and $0.1 \%$ Triton X-100 in PBS and incubated overnight at $4^{\circ} \mathrm{C}$. Primary antibodies used were rabbit anti-MyosinVIIa (Myo7a) (1:200 dilution, Proteus Biosciences), goat antiSox2 (1:500 dilution, Santa Cruz Biotechnology), mouse anti-acetylated $\alpha$-tubulin (1:250 dilution, Sigma-Aldrich), rabbit anti- $\beta$-catenin (1:500 dilution, BD Transduction Laboratories.), mouse anti-Tuj1 (1:500 dilution, Covance), mouse anti-ZO1 (1:100 dilution, Invitrogen), and rabbit antiperipherin (1:1000 dilution, Millipore). Appropriate secondary Alexaconjugated antibodies (1:1000 dilution, Invitrogen), diluted in 1\% BSA, 5\% goat or horse serum, $0.1 \%$ Triton X-100 in PBS, were incubated for $1-2 \mathrm{~h}$ at room temperature. Nuclei were labeled with Hoechst 33342 (1:2000 dilution, Invitrogen). Actin was labeled with rhodamine-conjugated phalloidin (1:40 dilution, Invitrogen) or Alexa 488-conjugated phalloidin (1:500 dilution, Invitrogen). PBS washes were performed between steps during the immunostaining protocol. For analysis of Tomato-positive samples (Tomato + ), endogenous fluorescence was measured. Fluorescent images were acquired using Zeiss LSM 700 or 710 confocal microscopes. Zen 2009/2011 software was used for image acquisition, LSM Image Browser, Adobe Photoshop CS5, and Imaris 7.6.0 were used for image processing.

Scanning electron microscopy. Mice were anesthetized with Avertin (0.6 $\mathrm{mg} / \mathrm{g}$ bodyweight, i.p.) and perfused with Super Reagent Perfusion Wash $\left(0.8 \% \mathrm{NaCl}, 0.4 \%\right.$ dextrose, $0.8 \%$ sucrose, $0.023 \% \mathrm{CaCla}_{2}, 0.034 \%$ sodium cacodylate) followed by Super Reagent Perfusion Fixation (4\% PFA, $4 \%$ sucrose, $1.4 \%$ sodium cacodylate) (Electron Microscopy Science). Inner ears were dissected out of the temporal bone and postfixed/ decalcified in 150 mM EDTA, 2.5\% glutaraldehyde, 2\% PFA, 3\% sucrose in $0.1 \mathrm{M}$ sodium cacodylate buffer, $\mathrm{pH} 7.35$ (Tousimis Research), using a Pelco Biowave Tissue Processor (Ted Pella). Cochleae were dissected, divided into two pieces, and postfixed with $1 \% \mathrm{OsO}_{4}$ (Electron Microscopy Science) in sodium cacodylate buffer for $2 \mathrm{~h}$ at room temperature followed by washes in double-distilled water $\left(\mathrm{ddH}_{2} \mathrm{O}\right)$ and incubation in $0.5 \%$ thiocarbohydrazide in $\mathrm{ddH}_{2} \mathrm{O}$ for $20 \mathrm{~min}$ at room temperature (Davies and Forge, 1987; Forge et al., 1998). Samples were dehydrated in an $\mathrm{EtOH}$ series (10\% to absolute) and critically point dried with $\mathrm{CO}_{2}$ (Sandai 790, Tousimis) before mounting and sputter coating (EMS 550, Electron Microscopy Sciences) with gold/palladium or platinum. Samples were imaged with a JEOL JSM 6700 scanning electron microscope using EOS6700F software.

Auditory brainstem response. Adult mice (P22 and older) were anesthetized with Avertin $(0.6 \mathrm{mg} / \mathrm{g}$ bodyweight, i.p.) and kept on a heating pad at $37^{\circ} \mathrm{C}$. Auditory brainstem responses (ABRs) were measured using a Tucker Davis Technology System III with RX6 Multiprocessors and BioSigRP software. Tone signals were calibrated using a $1 / 4$ inch ACO microphone (7017, ACO Pacific) connected to the RX6 multiprocessor analog/ digital input. Calibrated sinusoidal signals (rise time, $0.5 \mathrm{~ms}$; duration, 5 $\mathrm{ms}$ ) were fed into an EC-1 electrostatic speaker using the digital/analog output of an RX6 multiprocessor (sampling rate, $200 \mathrm{kHz}$ ) and attenuated using a PA5 programmable attenuator. The speaker was connected to a plastic probe that was inserted into the mouse ear canal and placed close to the eardrum $(\sim 1 \mu \mathrm{m})$. Frequencies tested were $4,6,12,16,22$, 32 , and $44 \mathrm{kHz}$ with sound pressure level (dB SPL, relative to $20 \mu \mathrm{Pa}$ ) attenuated in $5 \mathrm{~dB}$ steps between 75 and $0 \mathrm{~dB}$ SPL. ABR waveforms were recorded using subdermal needles placed at the vertex of the skull, below the pinna, and at the base of the tail. The needles were connected to a low-impedance head stage (RA4LI, Tucker Davis Technology) and fed into the optical port of the RX6 multiprocessor through a preamplifier (gain, 20×; RA4PA, Tucker Davis Technology). ABR waveforms were averages obtained from 500 presentations of the tone (21/s) in alternating phase and were band-pass filtered $(300 \mathrm{~Hz}-3 \mathrm{kHz})$. Thresholds in the ABR tuning curves were defined as the minimum $\mathrm{dB}$ SPL of a tone that elicited a response (wave I) above the noise floor. All experiments were conducted in a sound booth (Model 120A double wall, Industrial Acoustic).

Data analysis. Cell counts from confocal images were performed using ImageJ 1.45s software. Total numbers of HCs, PCs, and DCs were counted in a $160 \times 65 \mu \mathrm{m}$ area imaged with a $40 \times / 1.4$ NA objective on a Zeiss LSM 700/710 confocal microscope. Apoptotic nuclei were counted along the entire length of the apical or basal cochlear turn using the $40 \times / 1.4$ NA objective. Cell counts and ABR thresholds were plotted using Origin 9.0 software. Statistical analysis was performed using GraphPad Prism 5.0. Two-way ANOVA followed by Student's $t$ test with Bonferroni correction was used to compare cell numbers and ABR thresholds between experimental and control mice. Student's $t$ test was used to compare numbers of spiral ganglion neurons. Imaris 7.6.0 software was used to generate surface reconstructions of cochlear $Z$-stacks acquired in the LSM 700 and 710 confocal microscopes.

\section{Results}

\section{Prox 1 CreER ${ }^{\mathrm{T} 2}$ is specific to PCs and DCs in the organ of Corti}

To specifically target PCs and DCs in the organ of Corti we used the Cre/loxP system and in particular the Prox 1 CreER ${ }^{\mathrm{T} 2}$ mouse line (Srinivasan et al., 2007). We extended the characterization of Prox 1 CreER ${ }^{\mathrm{T} 2}$ activity in the organ of Corti using the Ai14 reporter mouse line. Ail4 is a more sensitive reporter of Cre activity than the Rosa $26^{\text {EYFP }}$ and the Rosa $26^{\text {LacZ }}$ mouse lines previously described (Madisen et al., 2010; Cox et al., 2012) and should, therefore, provide a more accurate estimate of the number of cells targeted by the Cre estrogen receptor (CreER). Prox $1 \mathrm{CreER}^{\mathrm{T} 2}+/-$; Ail4 ${ }^{\text {flox/+ }}$ (Prox1Ai14) mice expressed Tomato in those cells where the CreER was present and only after tamoxifen induction.

Prox 1 CreER ${ }^{\mathrm{T} 2}$ activity after postnatal induction with tamoxifen at P0 and P1 (0.075 mg/g bodyweight, i.p.) was previously characterized in the cochlea using the Rosa26 ${ }^{\text {EYFP }}$ and Rosa2 $6^{\mathrm{LacZ}}$ reporter mice (Yu et al., 2010). In Prox 1 CreER ${ }^{\mathrm{T} 2}+/-$; Rosa ${ }^{\text {EYFP/+ }}$ (Prox1EYFP) mice, Cre activity quantified at P6 was mosaic and specific to PCs and DCs in the cochlea. Approximately $13 \%$ of the PCs and DCs were enhanced yellow fluorescent protein-positive $(\mathrm{EYFP}+)$ at the apex and only $\sim 5 \%$ at the base.

In Prox1Ai14 mice, we used this same tamoxifen induction protocol and harvested the cochleae at P7. We found specific labeling of PCs and DCs (Fig. $1 B, C$ ) but larger numbers of Tomato + PCs and DCs than those previously reported (Fig. 1D). Quantification of SCs was done in $160 \mu \mathrm{m}$ windows at positions 25\% (apex), 50\% (middle), and 75\% (base) of the average 6000 $\mu \mathrm{m}$ cochlea length measured from the apical tip, which are the same locations used by Yu and colleagues (2010). This area selection allows accurate quantification and comparison with previous data and is representative of the events occurring in the respective cochlear turns. Percentages of PCs and DCs labeled with Tomato were calculated relative to the total amount of cells of each specific type (Fig. 1D). For inner PCs, $60 \%$ were Tomato + at the apex, $27 \%$ at the middle, and $13 \%$ at the base of the cochlea. There was a significant base-to-apex gradient of Cre activity present in the inner PC population (2-way ANOVA followed by Student's $t$ test with Bonferroni correction, ${ }^{* *} p<$ $0.001)$. In contrast, $80-90 \%$ of outer PCs and DCs of rows $1-3$ (1 being the closest to the inner HCs) were Tomato+ at the apex and middle of the cochlea without statistical differences. At the base, the percentages of outer PCs and DCs of rows 1 and 2 that were Tomato + were significantly lower than at apex and middle (55-65\%, 2-way ANOVA followed by Student's $t$ test with Bonferroni correction, ${ }^{* *} p<0.001$ ), while there were not significant differences among turns in DCs of row 3.

Additionally, in Prox1Ai14 mice, a few neurons were labeled in the spiral ganglion. This result is different from the absence of Cre activity in this area described by Prox1EYFP mice and may reflect a lower Cre activity in these cells that was only detected by the higher efficiency Ai14 reporter. Nonetheless, only a few neurons were Tomato + in the spiral ganglion $(4 \pm 0$, mean \pm SEM, $N=3$, counted in $10^{4} \mu \mathrm{m}^{2}$ ) and therefore the Prox1CreER ${ }^{\mathrm{T} 2}$ 
mouse line is not likely to produce prominent phenotypes in this area when crossed with specific floxed alleles.

\section{Progressive loss of cochlear SCs is followed by outer HC loss in Prox1DTA mice}

To study the effects of PC and DC ablation in cochlear development and function, we specifically expressed DTA in these two cell types by crossing ProxiCreER ${ }^{\mathrm{T} 2}+/-$ and Rosa26 $6^{\mathrm{DTA} /+}$ mice. Prox1DTA and control littermates were injected with tamoxifen $(0.075 \mathrm{mg} / \mathrm{g}$ bodyweight, i.p.) once a day at $\mathrm{P} 0$ and $\mathrm{P} 1$. The same induction protocol was used in Prox1Ail4 and Prox1EYFP mice. In Prox1DTA mice, DTA expression was induced by Cre-mediated deletion of a strong stop codon and produced cell-autonomous death via apoptosis (Ivanova et al., 2005; Abrahamsen et al., 2008; Burns et al., 2012).

Prox1DTA mice were born in normal percentage as predicted by Mendel's principles of heredity, with Prox1DTA mice representing $23 \%$ of the pups from crosses of heterozygous parents of each allele. However, only $17 \%$ of Prox1DTA mice survived until P25 or later ages. ProxiCreER ${ }^{\mathrm{T} 2}$ is expressed in other organs, such as liver, pancreas, and the lymphatic system (Srinivasan et al., 2007). Cre-mediated DTA expression in these other organs might be the reason why only a few Prox1DTA mice lived longer than even P15. This low survival rate considerably limited the number of samples available for experiments performed at later ages with Prox1DTA mice.

In agreement with the proposed model, in Prox1DTA mice, a percentage of PCs and DCs died in all turns of the cochlea, which was evidenced by the significant number of apoptotic nuclei that appear in the SC nuclear layer. In Figure 2A, a Prox1DTA representative sample shows reduced number of nuclei at P8 (labeled with Hoechst) in the DC region compared with a control sample. Apoptotic nuclei were also found in this region in Prox1DTA mice, showing different degrees of chromatin condensation (white circles). These apoptotic nuclei represent only those cells that happened to undergo evident nuclear changes in the process of apoptosis at the time cochleae were harvested.

Due to the small amount of apoptotic nuclei present at any specific time, we divided the cochleae of Prox1DTA and control mice in two pieces (apical and basal halves) and quantified total number of nuclei showing condensed chromatin. This quantification shows that signs of PC and DC apoptosis in ProxiDTA mice were evident $24 \mathrm{~h}$ after the last tamoxifen injection (apex: mean \pm SEM, $14.5 \pm 2.6$; base: $8.2 \pm 1.6$ nuclei at P2-P3, $N=$ 4-5), peaked between P4 (apex, $31.0 \pm 7.6$; base, $22.7 \pm 6.8 ; N=$ 3 ) and P8 (apex, $30.2 \pm 5.5$; base, $18.3 \pm 3.2 ; N=6$ ), and decreased between P14 (apex, $7.8 \pm 3.1$; base, $1.3 \pm 0.6 ; N=4$ ) and P28 (apex, $2.0 \pm 1.2$; base, $1.7 \pm 0.9 ; N=3-4$ ) (Fig. $2 B$ ). A two-way ANOVA followed by Student's $t$ test with Bonferroni correction showed no statistical differences $(p>0.05)$ between counts in Prox1DTA cochleae and controls at the apex or the base at P14 and later ages. There were also no statistical differences between apical and basal halves in Prox1DTA mice at any age analyzed. However, there is a tendency to smaller numbers of apoptotic nuclei found in the basal half. These data show that PC and DC death induced by DTA expression is a process that takes place over many days. The time window of death induced by DTA might be due to time taken for the DTA to kill SCs, different expression levels and susceptibility to DTA-driven apoptosis among individual SCs and/or accumulative changes in organ architecture.

Apoptosis of PCs and DCs in Prox1DTA mice leads to significant cell loss in the organ of Corti. Figure 3 shows representative images of
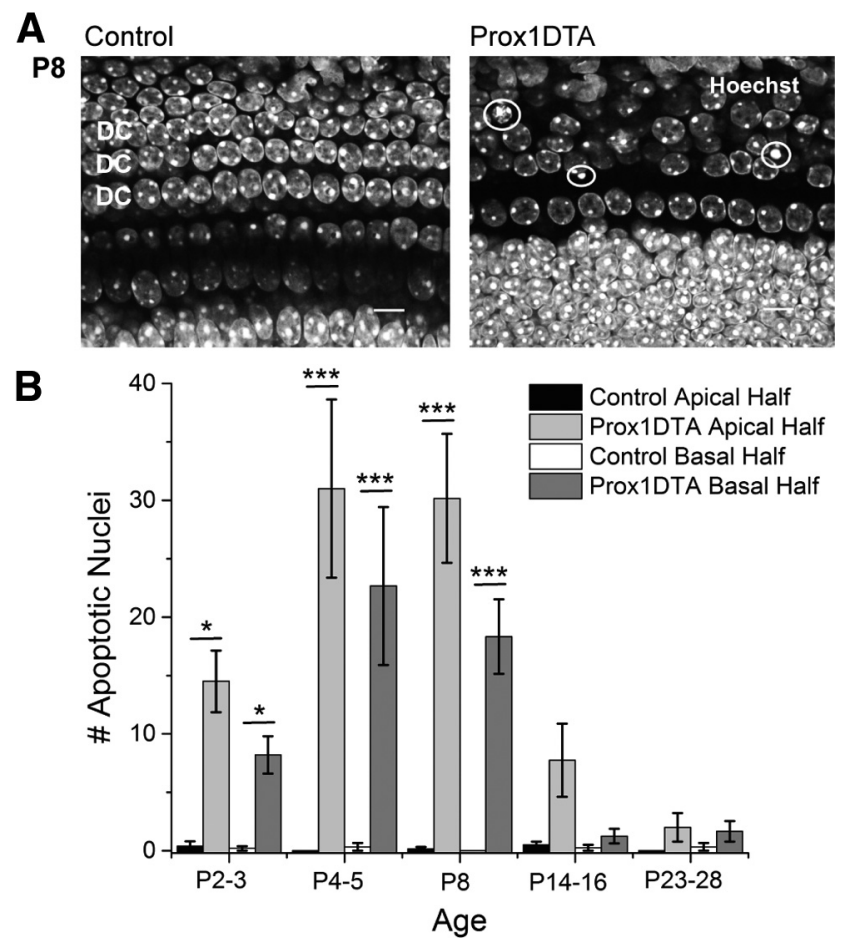

Figure 2. Apoptosis of PCs and DCs occurs in Prox1DTA mice after DTA expression. $A$, Representative optical sections of the apical cochlea at P8 of a Prox1DTA and of a control mouse. Images taken at the level of the $P C$ and $D C$ nuclei show examples of apoptotic nuclei with condensed chromatin in the Prox1DTA cochlea (white circles). Nuclei are labeled with Hoechst 33342 (white). Scale bars, $10 \mu \mathrm{m} . \boldsymbol{B}$, Number of apoptotic $P$ C and DC nuclei in the apical half and basal half of the cochleae of Prox1DTA and control mice observed at the time of cochlea harvesting (ages between P2 and P28). Data are expressed as mean \pm SEM for $N=3-6$ at each age. Statistical differences between counts in Prox1DTA and control cochleae at apex or base are represented with bars and asterisks (two-way ANOVA followed by Bonferroni correction, ${ }^{*} p<$ $\left.0.05,{ }^{* * *} p<0.001\right)$. There are no statistical differences between Prox1DTA and control at apex or base at P14 and later ages $(p>0.05)$. There are no statistical differences between Prox1DTA apical and basal counts at any age analyzed $(p>0.05)$.

the apical organ of Corti at different ages in control and experimental mice. These images were taken at locations similar to those where cell counts were made with the Cre-reporter alleles (1000-1500 $\mu \mathrm{m}$ from the apical tip). Disorganization and loss of PC and DC nuclei were observed from P2 (Fig. 3A) in Prox1DTA compared with control mice and progressed up to 1 month of age (Fig. $3 B-D$ ). Outer HC loss followed SC loss beginning at P14-P15 (Fig. 3C). At P27 almost all outer HCs were missing while inner HCs remained present in the organ of Corti (Fig. 3D).

At P14-P15 and later ages we found a few examples in Prox1DTA cochleae of outer HCs missing from the HC layer that were instead present among DC nuclei in the SC layer (Fig. 3C, white arrow). This may be a step in the degeneration process that outer HCs undergo due to significant loss of DCs and outer PCs in the Prox1DTA model. HCs appear in the SC cell layer in regions where neighboring SC nuclei are missing (Fig. 3C). This finding supports the idea that lack of support normally provided by the DCs to the outer HCs contributes to their death. An additional explanation that we cannot rule out is that these outer $\mathrm{HCs}$ are dying and have been engulfed by the remaining SCs (Abrashkin et al., 2006; Bird et al., 2010). However, the reduced number of SCs present in Prox1DTA cochleae makes this event less likely to occur than in wild-type mice.

To quantify the observed loss of cochlear cells, we counted specific SCs and HCs in Prox1DTA and control cochleae in 160 


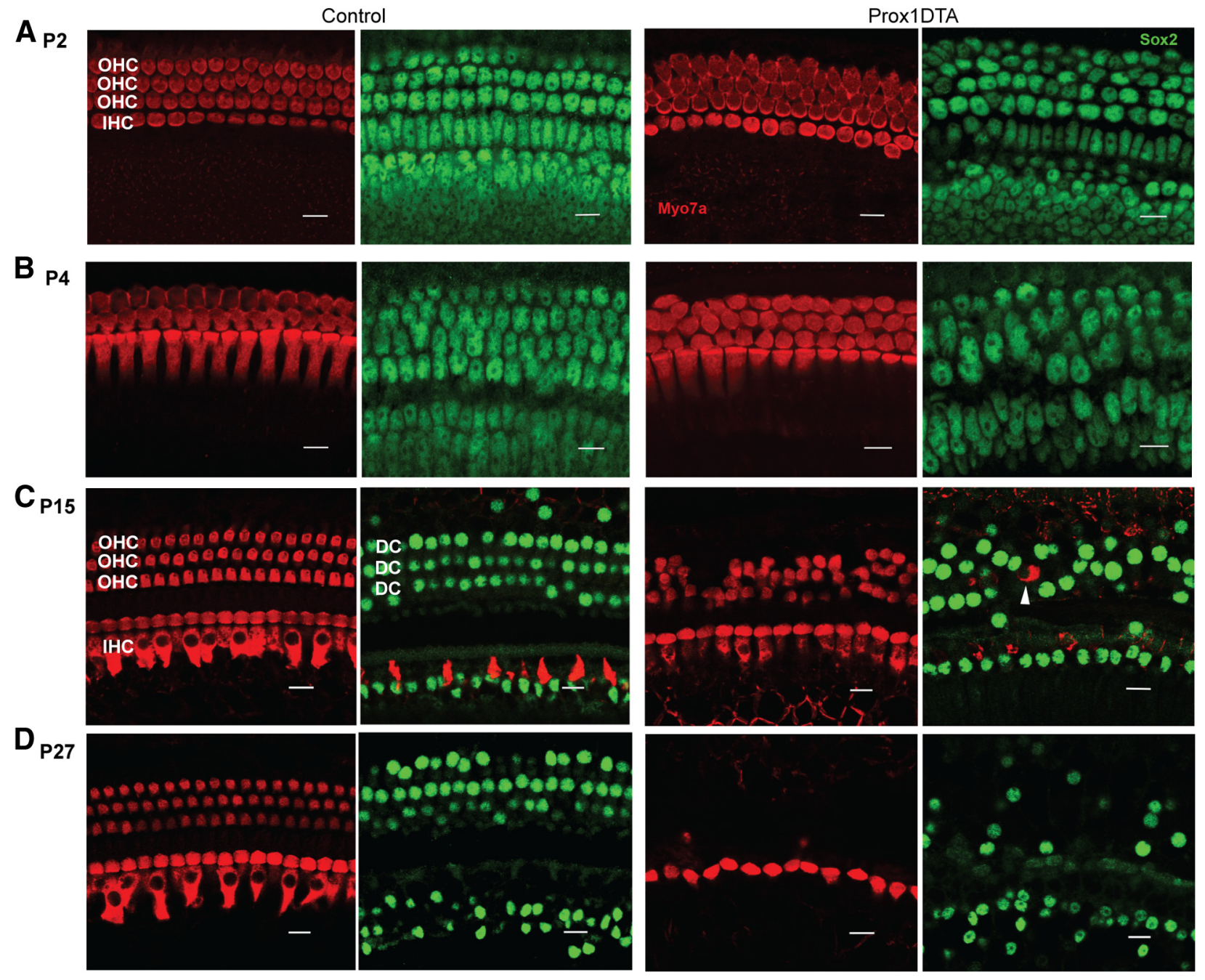

Figure 3. $\mathrm{PC}$ and DC loss in Prox1DTA mice is progressive and followed by outer HCloss. $\boldsymbol{A}-\boldsymbol{D}$, Representative optical sections from the apical cochleae of Prox1DTA and control mice at the HC layer (My07a + bodies in red) and the SC nuclear layer (Sox2+ nuclei in green). Side-by-side images show HCs and SCs underneath in control and Prox1DTA cochleae at ages P2 (A), P4 (B), P15 (C), and P27 (D). The number of PCs and DCs (green nuclei) decreased between P2 and P27 in Prox1DTA mice. Outer HC (OHC) loss is evident at P15 and increases with age. Inner HCs (IHC) are present at all ages. White arrowhead in C represents an outer HC missing in the HC layer and found in the SC nuclear layer underneath. Scale bars, $10 \mu \mathrm{m}$.

$\mu \mathrm{m}$ representative regions. We compared counts done at the apical $(25 \%)$ and basal (75\%) turns of the cochlea (Fig. 4). PCs were counted as the two rows of Sox $2+$ nuclei between inner and outer HCs and DCs as the three rows of Sox $2+$ nuclei underneath the outer HCs (relative positions shown in Fig. $1 A$ ). There was significant loss of DCs and outer PCs in Prox1DTA mice relative to control littermates beginning at $\mathrm{P} 2$ at the apex and $\mathrm{P} 4$ at the base and progressing up to 6 weeks (Fig. $4 A$ ). In the basal turn, DC and outer PC loss follows the same progressive pattern with age as in the apex but tends to be slightly less severe, although significant differences in the number of cells counted at apex and base were found only at P14-P15 (blue square, Fig. 4 A). Inner PC counts showed smaller loss, only significant at P14 and later in the apical region of the cochlea (Fig. 4B). Regarding inner PC loss, the basal cochlea is significantly less affected than the apex (Fig. $4 B$, blue squares). These results are consistent with the gradient of Cre activity described for this cell type along the cochlea in Prox1EYFP and Prox1Ai14 mice.

It is important to note that quantification of SCs present at each age in Prox1DTA mice represents the additive loss of these cells until the time of analysis. These numbers are therefore larger than the number of apoptotic nuclei counted at any age (Fig. $2 B$ ). However, our data are consistent in that the largest numbers of apoptotic nuclei are found between P2 and P14 in Prox1DTA mice (Fig. $2 B$ ) and this is the time window of largest progression of DC and PC loss (Fig. $4 A, B$ ). On the other hand, apoptotic nuclei numbers are small at P14 and later (Fig. $2 B$ ), when the progressive loss of SCs approaches a plateau (Fig. $4 A, B$ ).

Quantification of outer HCs $(\mathrm{Myo} 7 \mathrm{a}+)$ revealed that their loss appeared in Prox1DTA mice $12 \mathrm{~d}$ after initial SC loss at the apex and $10 \mathrm{~d}$ after at the base, showing significant differences from control only at P14 and later (Fig. 4C). Outer HC loss is significantly less prominent at $\mathrm{P} 14-\mathrm{P} 15$ at the base than the apex of the cochlea (Fig. 4C, blue square) and shows the same trend at later ages. In contrast, the number of inner HCs was similar in Prox1DTA and control mice at all ages analyzed and in all regions of the cochlea (Fig. 4D). Our data show that Prox1DTA mice have a slight base-to-apex gradient of cell death that is consistent with the level of CreER activity described by Prox1EYFP and Prox1Ai14 reporter mice.

The differential loss of inner and outer HCs seen in Prox1DTA mice directly correlates with their respective proximity to the SCs ablated in our mouse model (Fig. 1A). In Prox1DTA mice, DTA- 

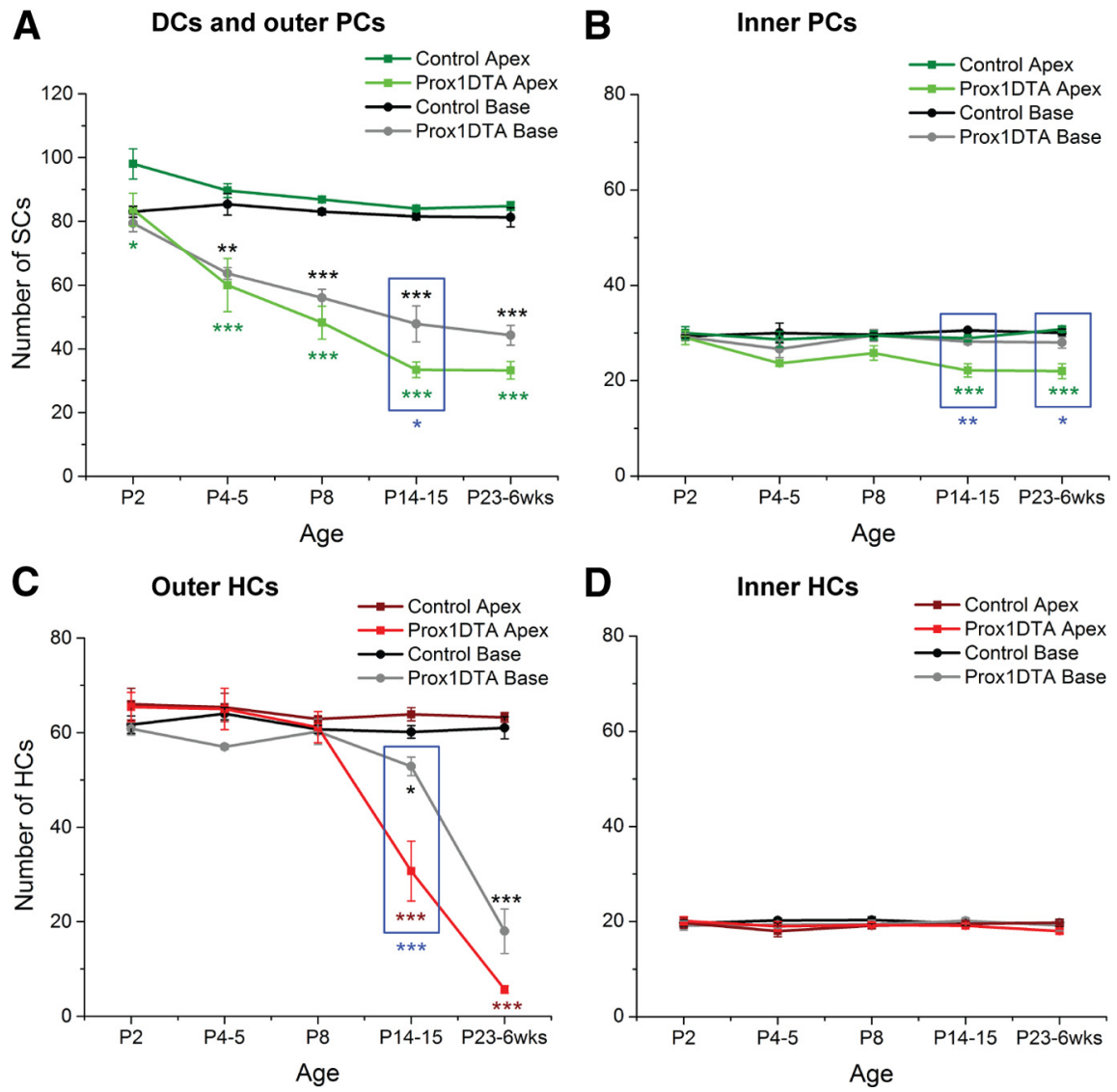

Figure 4. Quantification of progressive SC and HC loss with age in Prox1DTA mice. A-D, Total numbers of SCs (Sox2+ nuclei) and $\mathrm{HCs}$ (My07a + cell bodies) in $160 \mu \mathrm{m}$ regions of the apical and the basal turns of the cochlea in Prox1DTA and control mice at different ages. Data are expressed as mean \pm SEM $(N=3-8)$. Comparisons between cell counts in each Prox1DTA cochlear turn and corresponding controls were performed using a two-way ANOVA followed by Student's $t$ test with Bonferroni correction $\left({ }^{*} p<0.05,{ }^{* *} p<0.01,{ }^{* * *} p<0.001\right)$. Green or red asterisks show statistical differences between apical counts of SCs or HCs and their controls. Black asterisks represent differences between basal counts of SCs or $\mathrm{HCs}$ and their controls. Significant differences between apical and basal counts in Prox1DTA cochleae are marked with blue asterisk and highlighted inside blue squares.

induced cell death mainly occurrs in DCs and outer PCs, which surround the outer HCs and causes their loss over time, while the inner HCs are surrounded by inner PCs, which are less severely ablated in this model, and inner phalangeal cells, which are not targeted by the Prox1CreER ${ }^{\mathrm{T} 2}$.

\section{Changes in cochlea microarchitecture seen in Prox1DTA mice}

Further evidence to support correlation between SC loss, disruption of cochlear microarchitecture, and outer $\mathrm{HC}$ loss in Prox1DTA mice was revealed by $3 \mathrm{D}$ reconstruction of $Z$-stack confocal images of representative samples using Imaris 7.6.0 software (Fig. 5). At P15 in Prox1DTA mice, a significant reduction of Sox2+ $\mathrm{PC}$ and DC nuclei is evident (Fig. 5A). At this age there is also a significant reduction in outer $\mathrm{HC}$ numbers and some outer $\mathrm{HC}$ bodies are found lower in the epithelium, among SC nuclei, without connection to the reticular lamina (Fig. 5B, white circles). Hensen cell nuclei, also labeled with Sox2 and not ablated in Prox1DTA mice, are closer to the inner HCs in Prox1DTA mice, suggesting that the lateral region of the organ of Corti is contracting in a lateral-to-medial direction.

PC apices and DC phalanges are strongly labeled by acetylated tubulin as shown in Figure $5 B, C$ (white). Outer PC apices and DC phalanges among outer HCs are reduced in number in
Prox1DTA mice at P15 (Fig. 5B) while the inner PC phalanges between inner and outer HCs are better preserved in number and structure. At this age, the space created by the PCs between inner and outer HCs (tunnel of Corti) is largely preserved. At 6 weeks of age in a similar region of the cochlea (apex), the elongated processes of PCs and DCs are more disrupted and the space between inner and outer HCs is considerably reduced (Fig. 5C). Few outer $\mathrm{HCs}$ can be found among Sox $2+$ SC nuclei at this age (white circle). In the middle turn of the same 6-week-old cochlea, a picture more similar to a P15 cochlea is seen, where more outer PC and DC phalanges are preserved and the space between inner and outer HCs is still present. These data support our previous counts showing a slight base-to-apex gradient of cell death along the cochlea spiral (Fig. 4). It is important to note that the Prox1DTA model is mosaic and that some variation in the degree of disruption was observed at each age in adjacent areas of the same cochlea and among animals.

Relevant features found at both P15 and 6 weeks of age in Prox1DTA mice are significant loss of outer HCs, but not inner HCs, and that remaining DC phalanges extend to contact the inner PCs, reducing the space normally populated by outer HCs. Additionally, in all samples analyzed up to 6 weeks of age, the organ of Corti seems to preserve its columnar organization and not convert into a flat epithelium. In conclusion, our data show considerable changes in the architecture of the organ of Corti in Prox1DTA mice compared with control littermates.

\section{Changes at the $\mathrm{HC}$ apices and the reticular lamina in Prox1DTA mice}

The reticular lamina, the apical surface of the organ of Corti (Fig. $1 A$ ), is formed by alternating apposition of the apices of HCs and SCs tightly bound by apical junctions. The reticular lamina chemically divides the scala media from the scala tympani, separating the upper high $\mathrm{K}^{+}$, low $\mathrm{Na}^{+}$endolymph from the low $\mathrm{K}^{+}$, high $\mathrm{Na}^{+}$perilymph underneath (Von Bekesy, 1952; Hibino and Kurachi, 2006). Sealing the reticular lamina after HC damage by noise or ototoxic drugs is extremely important to maintain the separation between these two extracellular fluids to avoid massive cell death and preserve mechanoelectrical transduction (Serra and La Mantia, 1982; Raphael and Altschuler, 1992; Raphael, 2002; Ahmad et al., 2003). Sealing of the epithelium and scar formation after $\mathrm{HC}$ death is thought to depend on surrounding SCs (Leonova and Raphael, 1997; Raphael, 2002; Taylor et al., 2012). We, therefore, analyzed what happened to the reticular lamina in Prox1DTA mice, where prominent loss of PCs and DCs preceded HC loss.

Hair bundles, the sensory machinery of HCs, protrude on top of the $\mathrm{HC}$ cuticular plates that contribute to form the reticular lamina and are uniformly oriented with their $\mathrm{V}$ shape opened 
toward the medial side of the organ of Corti. At P8, staining with phalloidin, which labels the actin core of the $\mathrm{HC}$ hair bundles, showed disruption of their radial orientation in Prox1DTA cochleae (Fig. $6 \mathrm{~A}$, white arrowheads). Movement of the hair bundles away from their normal radial position in the organ of Corti of Prox1DTA mice is most likely a result of rotation of the outer $\mathrm{HC}$ bodies due to disruption of the DC phalanges surrounding them. Indeed, ZO1 labeling of the apical junctions (Fig. 6A, green) shows that the number and shape of PC and DC phalanges in between outer HCs are abnormal in Prox1DTA cochleae. Another consequence of this loss of SC phalanges was that neighboring outer HCs touched each other (Fig. $6 \mathrm{~A}$, white square), a pattern not seen in the normally alternating $\mathrm{HC} / \mathrm{SC}$ reticular lamina of control mice. In contrast, inner HCs did not show significant differences in hair-bundle orientation or cell position between Prox1DTA and control mice.

Presence of ZO1 labeling in Prox1DTA cochleae at P8 supports the idea that the reticular lamina preserved its ability to seal after significant loss of PCs and DCs. $\mathrm{ZO} 1$ is also present at the apical junctions at P14. Additionally, we labeled apical junctions at P14 with $\beta$-catenin and showed that the apical junctions at the reticular lamina are present (Fig. 6B). At this age, it was also evident that the space normally occupied by the outer HCs was progressively narrowed in Prox1DTA cochleae compared with control cochleae (Fig. 6B).

SEM images of Prox1DTA cochleae at P15 (Fig. 6C) show radial misorientation of the outer HC hair bundles in the regions where DC phalanges were disrupted. The images also show contact among outer HCs, which is similar to what was seen at P8. SEM images of the cochlea at P15 and 8 weeks of age show that the tops of the Hensen cells (note location in Figure $1 \mathrm{~A}$ ), which in control mice form a line lateral to the third row of outer HCs, had migrated towards the inner PCs in Prox1DTA mice (Fig. $6 C, D$, red arrowheads). These images also show that indeed the Hensen cell apices and the phalanges of the remaining DCs and outer PCs sealed the top of the organ of Corti after outer HC loss (Fig. $6 C, D)$. Consistent with the data shown before, inner PCs and inner HCs were well preserved even at 8 weeks of age in Prox1DTA mice.

Together, these results support the idea that the high $\mathrm{K}^{+}$endolymph did not leak into the spaces around the cells remaining in the epithelium in Prox1DTA mice and therefore massive cell loss was not seen. It also shows that outer PCs and DCs are required to maintain the normal pattern of organization present at $10 \mu \mathrm{m}$.
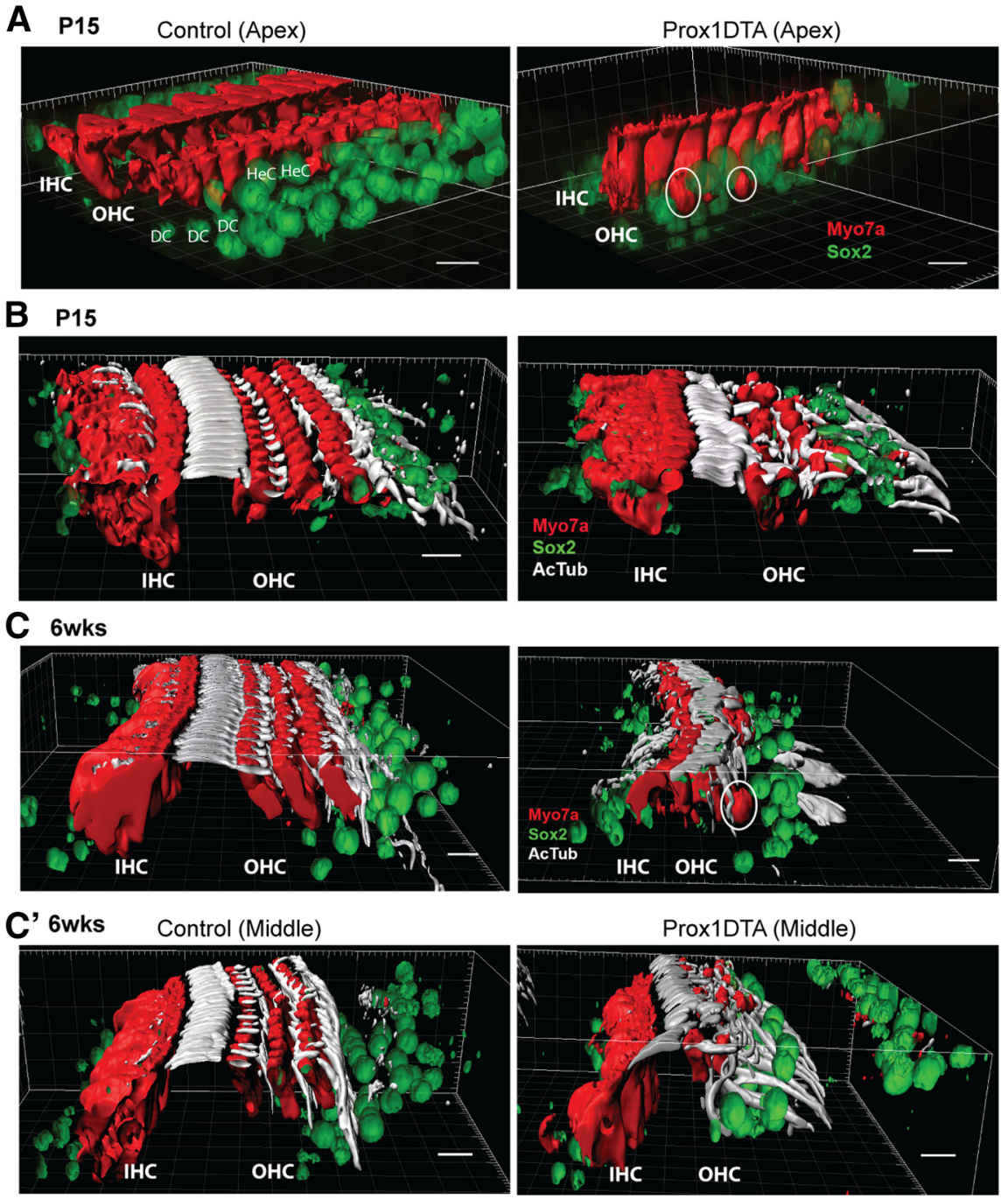

Figure 5. Changes in organ of Corti 3D structure caused by PC and DC loss in Prox1DTA mice. $A$, Imaris $3 D$ surface reconstruction of representative confocal images taken from Prox1DTA and control apical cochleae at $\mathrm{P15}$. Inner and outer $\mathrm{HCS}$ (IHC and $\mathrm{OHC}$ ) are shown in red (Myo7a) and SC nuclei in green (Sox2). White circles show outer HCs whose bodies only appear in the SC nuclei layer. bars, $10 \mu \mathrm{m}$. B, Imaris 3D surface reconstruction of HCs (red, My07a), SC nuclei (green, Sox2), and PC and DC phalanges labeled with acetylated tubulin (AcTub, white) in Prox1DTA and control apical cochleae at P15. Reduction in number of outer HCs and in anization of $\mathrm{PC}$ and $\mathrm{DC}$ phalanges is evident in Prox1DTA compared with control cochleae. The space between inner HCs and outer HCs is preserved. Scale bars, $10 \mu \mathrm{m}$. C, Imaris 3D surface reconstruction of HCs (red), SC nuclei (green), and PC and me cochlea ( 6 weeks) shows more $\mathrm{PC}$ and DC phalanges present and conserved space between inner and outer HCs. Scale bars,

the top of the organ of Corti, which is key to effective mechanoelectrical transduction.

\section{Cochlear innervation, neuron survival, and auditory} responses in Prox1DTA mice

Cochlear HCs and SCs release neurotrophic factors important to maintaining the neuronal connections to the organ of Corti (Stankovic et al., 2004). These cells may also provide cues to the neurons to establish proper synapses with the HCs during postnatal development (Knipper et al., 1996 1997; Sobkowicz et al., 2002; Puligilla et al., 2007). Analysis of the neuronal connections in Prox1DTA cochleae at P8 showed that they were fewer and less organized in the outer $\mathrm{HC}$ area compared with control cochleae (Fig. 7A). This result correlates with the disorganization of outer 


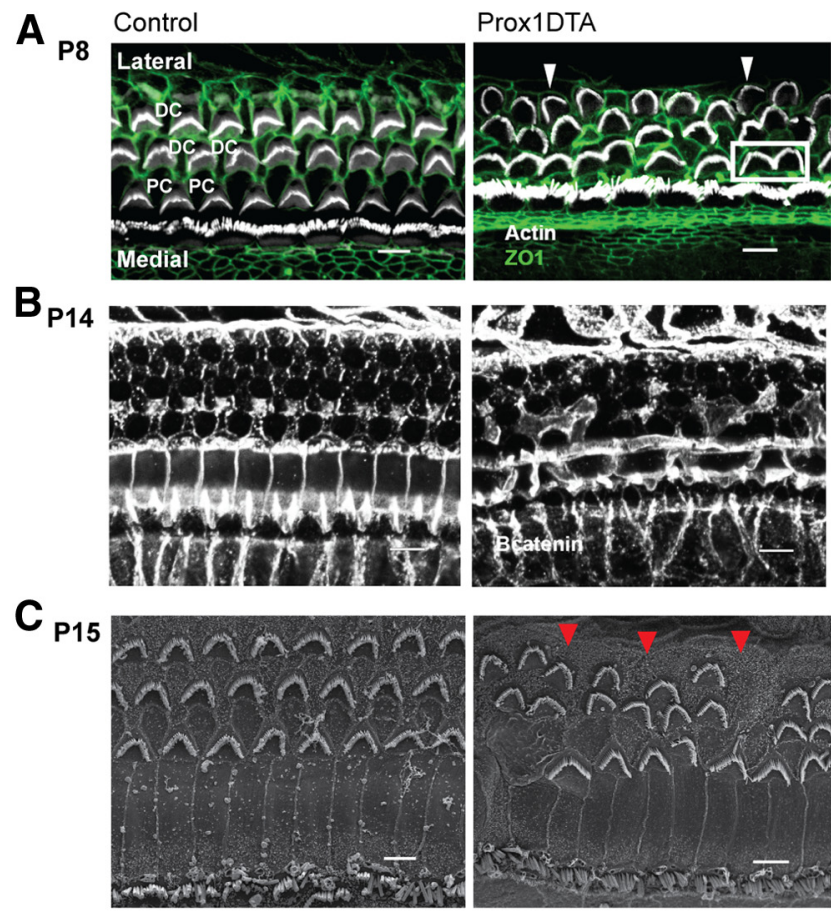

\section{8wks}

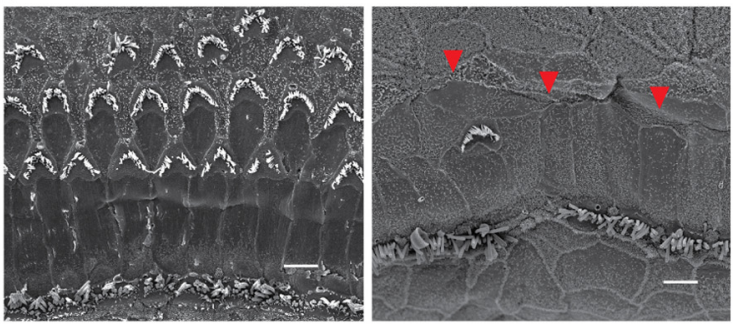

Figure 6. Progressive changes at the reticular lamina in Prox1DTA mice. A, Representative optical sections showing $\mathrm{HC}$ Chair bundles (actin/phalloidin, white) and apical junctions between HCs and SCs (Z01, green). Radial misorientation of hair bundles (white arrowheads) and HC-HC contacts (white square) are evident in Prox1DTA cochleae at P8, before outer HC loss occurs. 201 labeling at P8 shows disorganized and missing DC phalanges between outer HCs in Prox1DTA mice compared with controls. Scale bars, $5 \mu \mathrm{m}$. $\boldsymbol{B}$, Representative projections of optical sections taken at the top of the organ of Corti of Prox1DTA and control cochleae. Apical junctions, labeled with $\beta$-catenin (white), are present in Prox1DTA mice at P14. Scale bars, $10 \mu \mathrm{m} . \mathbf{C}, \boldsymbol{D}$, Representative SEM images of the apical turn of the cochlea at P15 ( () and 8 weeks ( $\boldsymbol{D}, 8$ wks) of age from Prox1DTA and control mice. Note that the remaining PCs, DCs, and the Hensen cells seal the epithelium in Prox1DTA mice. Loss of outer HCs and misorientation of outer HC hair bundles are evident in Prox1DTA mice compared with controls at P15 (C). Progressive outer HC loss and preservation of inner HCs can be seen in Prox1DTA cochleae. Red arrowheads point to the tops of Hensen cells that have moved toward the inner HCs in Prox1DTA mice. Scale bars, 5 $\mu \mathrm{m}$.

HCs caused by SC loss seen at this age (Fig. 7A). In Figure 7A', we show a section of the organ of Corti where one of the DCs is missing (DC1) and the neuronal connections to the two outer HCs adjacent to it are clustered together. This is different from the organized pattern of neuronal connections to the outer HCs seen alternating between DCs in control mice (Fig. 7 $A^{\prime}$ ).

In Figure 7A', it is also evident that at P8, when DCs are missing, the outer HCs on top can stay attached to the reticular lamina. This is likely correlated with the fact that other DCs present 2-3 outer HCs away from these outer HCs extend slanting phalanges to connect to them and keep them at the reticular lamina (Geisler and Sang, 1995). Data shown in Figures 3-5, on the other hand, suggest that further SC loss between P8 and P14 triggers HC loss, where some of the outer HCs sink into lower layers of the epithelium.

At P14, neuronal connections to the outer $\mathrm{HC}$ area in control cochleae were refined while in Prox1DTA cochleae they were thicker, disorganized, and showed signs of dendritic swelling (Fig. 7B) (Lavigne-Rebillard and Pujol, 1990). Neuronal connections to the inner $\mathrm{HC}$ area at P8 and P14 were similar between Prox1DTA and control cochleae (Fig. $7 A, B$ ).

The Proxl protein is expressed in the spiral ganglion at postnatal ages in mice but seems to be lower than its expression in the sensory epithelium (Bermingham-McDonogh et al., 2006). Consistent with this, Prox 1 CreER ${ }^{\mathrm{T} 2}$ activity determined using the Rosa2 $6^{\text {EYFP }}$ reporter mouse line and tamoxifen induction at P0 and P1 was not detected in the spiral ganglion (Yu et al., 2010) and only a few cells were labeled using the more efficient Ai14 reporter. In addition, CreER expression in Prox1CreER ${ }^{\mathrm{T} 2}$ mice follows an internal ribosome entry site sequence (Srinivasan et al., 2007) and therefore is expected to be lower than endogenous 5 '-cap-dependent transcription of the Proxl gene (Gilbert, 2010).

To confirm that disruption of neuronal connections seen in the organ of Corti of Prox1DTA mice was due to SC and HC loss and not neuronal cell loss, we analyzed the neuronal cell bodies in the spiral ganglion of these mice and their controls. We used Tuj1, an antibody that labels tubulin $\beta$ III in type I and type II spiral ganglion neurons. Type I are the neurons that encode sound and represent $\sim 95 \%$ of the spiral ganglion in mice from $\sim$ P10. Type II neurons, on the other hand, represent $\sim 5 \%$ of the spiral ganglion from P10. At P14, when neuronal connections to the outer $\mathrm{HC}$ area of the organ of Corti are disrupted in Prox1DTA mice (Fig. 7B), there were no significant differences in the amount or morphology of spiral ganglion neurons (Tuj1+) in the apical region compared with control mice (Fig. 7C) (neurons in a $10^{4} \mu \mathrm{m}^{2}$ area, mean \pm SEM: control, $57.5 \pm 4.0$; Prox1DTA, $63.0 \pm 4.3 ; N=4$, Student's $t$ test $p>0.05)$. Tubulin $\beta$ III seems to be downregulated in type II neurons in adult mice (Lallemend et al., 2007; Barclay et al., 2011), so as additional support to spiral ganglion integrity we detected similar numbers of peripherin-labeled type II neurons in Prox1DTA and control mice at P14 (neurons in a $10^{4} \mu \mathrm{m}^{2}$ area: control, $3.1 \pm 0.3$; Prox1DTA, $3.3 \pm 0.2, N=3$, Student's $t$ test $p>0.05)$. At $4-6$ weeks, the number of spiral ganglion neurons was also similar in Prox1DTA and control mice (Fig. 7D) (control, $58.7 \pm 2.4$ Prox1DTA, $59.7 \pm 3.8, N=3$, Student's $t$ test $p>0.05$ ). Therefore, even if a small number of neurons in the spiral ganglion expressed DTA, their ablation did not produce a significant reduction in the total number of neuronal cell bodies.

To study the effects of SC loss and subsequent HC loss on hearing function, we measured ABR (wave I) thresholds in Prox1DTA and control mice at P22-P25 and 5-6 weeks of age. ABR waveforms were elicited in Prox1DTA mice as in control mice but at higher sound-pressure levels. Prox1DTA mice showed $40-50 \mathrm{~dB}$ hearing loss at all frequencies studied (4-44 $\mathrm{kHz}$ ) at P22-P25 (Fig. 8A) and at 5-6 weeks of age (Fig. 8 B). These ABR threshold shifts correlate with the changes seen in the cochlea of Prox1DTA mice, where outer HCs are lost and therefore cochlear amplification is missing (Liberman et al., 2002), while inner HCs remain present to account for passive cochlear responses measured only at high sound-pressure levels. As described above, spiral ganglion neuron loss is not the cause of the hearing loss seen in Prox1DTA mice (Fig. 7C,D).

To support the idea that outer $\mathrm{HC}$ loss is the main reason why Prox1DTA mice are deaf, we used a similar genetic approach and 
A

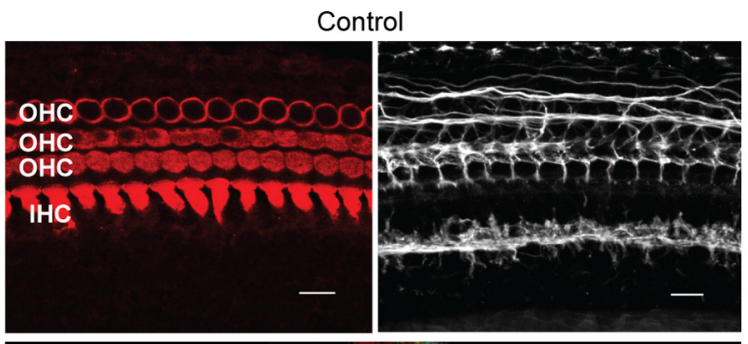

$\mathbf{A}^{\prime}$ P8

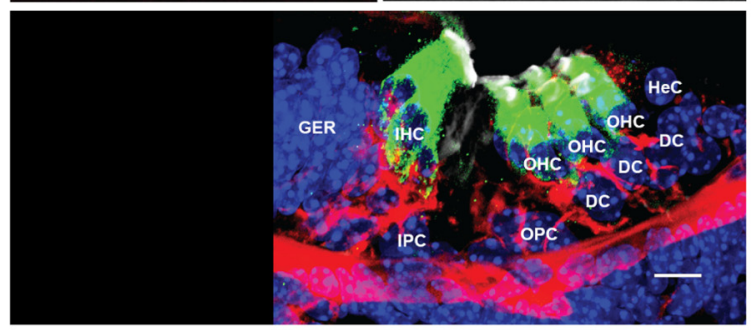

$\mathbf{B}_{\mathrm{P} 14}$

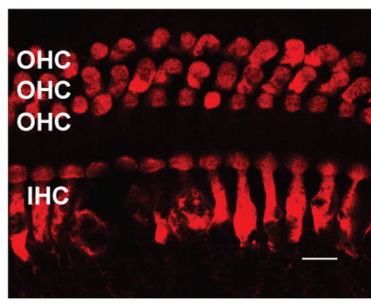

$\mathrm{C}_{\mathrm{P} 14}$

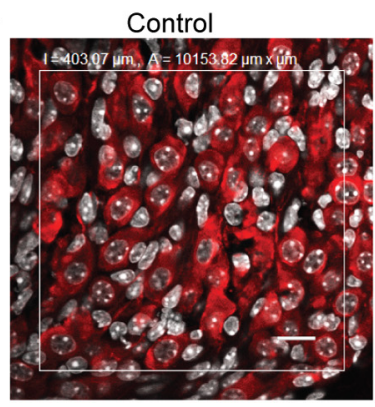

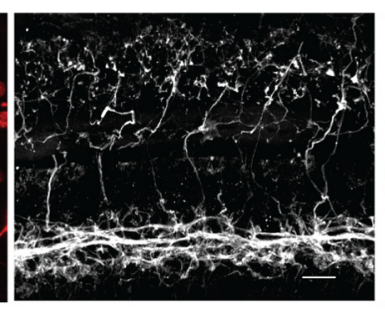

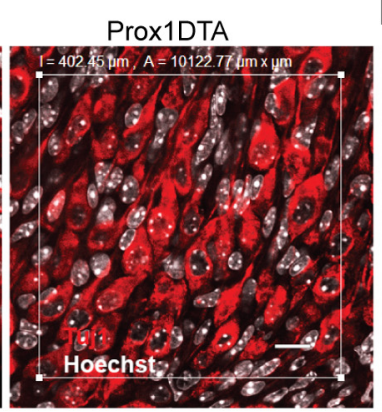

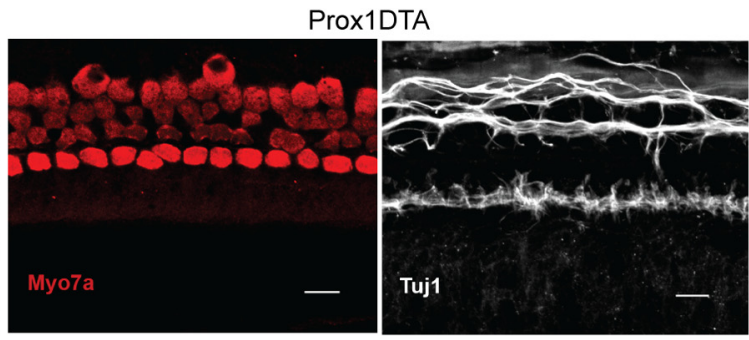
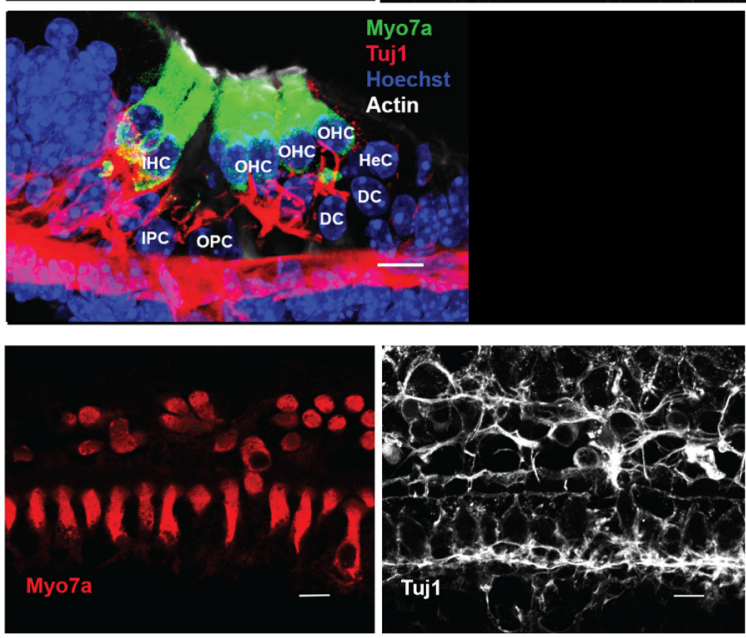

D 6 wks control

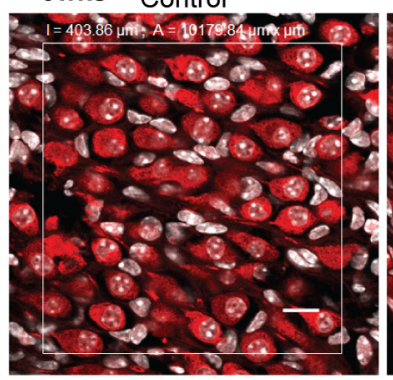

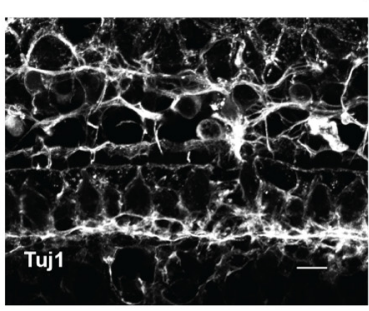

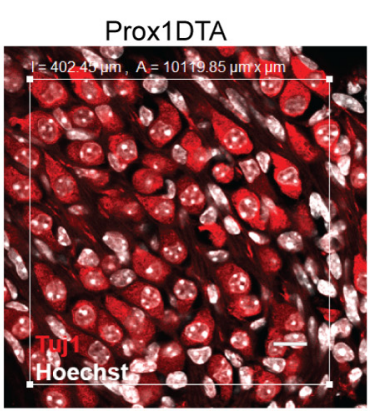

Figure 7. Neural connections to outer HCs are disrupted in Prox1DTA mice while neuronal cell bodies are preserved. A, Representative optical projections of the apical cochlea of Prox1DTA and control mice at P8. Side-by-side images show HC bodies (Myo7a, red) and neuronal connections in the same region (Tuj1, white). Prox1DTA cochleae show disorganized connections in the outer HC $(\mathrm{OHC})$ area at P8. $A^{\prime}$, Cross sections of the organ of Corti of control and Prox1DTA mice showing a missing DC in Prox1DTA and corresponding disorganized innervation to the OHCs above. OHCs stay connected to the reticular lamina at this age. Scale bars, $10 \mu \mathrm{m}$. IHC, inner hair cell; IPC, inner PC; OPC, outer PC; GER, greater epithelial ridge; HeC, Hensen cell. $B$, Representative optical projections of the apical cochlea of Prox1DTA and control mice at P14. Tuj1 (white) staining of dendritic terminals shows refinement of connections to OHCs (Myo7a, red) between P8 and P14 in control mice and disruption of this pattern in Prox1DTA mice. Swelling of neuronal connections is also evident at this age in the outer HC region of Prox1DTA mice. Scale bars, $10 \mu \mathrm{m}$. $C$, Representative optical projections of the spiral ganglion region (area, $10^{4} \mu \mathrm{m}^{2}$ ) in cochlear cross sections at P14 showing similar numbers of neuronal bodies in control and Prox1DTA mice. Neuronal cytoplasm is labeled with Tuj 1 (red) and nuclei with Hoechst (white). Scale bars, $10 \mu \mathrm{m}$. D, Representative optical projections of the spiral ganglion region (area, $10^{4} \mu \mathrm{m}^{2}$ ) in cochlear cross sections at 6 weeks (wks) showing similar numbers of neuronal bodies in control and Prox1DTA mice. Scale bars, $10 \mu \mathrm{m}$.

measured ABR thresholds after specific outer HC ablation. We used PrestinCreER ${ }^{\mathrm{T} 2}$ mice, where CreER activity is specific to outer HCs (100\% of outer HCs) 1 week after tamoxifen injections at P21 and P22 (Fang et al., 2012). These mice were bred with Rosa26 ${ }^{\mathrm{DTA}}$ mice to generate PrestinDTA and control mice, which were injected with tamoxifen at P21 and P22. Two weeks after CreER induction (5 weeks), PrestinDTA mice showed ABR thresholds $\sim 50 \mathrm{~dB}$ higher than those of control littermates (Fig. $8 C$ ). This result was consistent with the significant loss of outer HCs seen in PrestinDTA cochleae (Fig. 8D). Note the similarities in the loss of outer HCs and not inner HCs between this model and the adult Prox1DTA cochleae (Figs. 3D, 5C, 6D). ABR thresholds in PrestinDTA mice were not statistically different from those measured in Prox1DTA mice (2-way ANOVA followed by Student's $t$ test with Bonferroni correction, $p>0.05$ ), where the primary damage was to PCs and DCs and occurred earlier in postnatal development. Thresholds of control mice of PrestinDTA compared with control mice of Prox1DTA showed statistical differences only at $12 \mathrm{kHz}$ (2-way ANOVA followed by Student's $t$ test with Bonferroni correction, $p<0.01)$ and $44 \mathrm{kHz}$ $(p<0.001)$. These statistical differences were most likely related to strain background differences.

\section{Discussion}

\section{Specific SC ablation}

Primary SC death has remained unstudied, largely because these cells are more resilient than HCs to damage by noise and ototoxic drugs. In studies of organ of Corti damage published to date, SC death follows or is concomitant with HC loss (Abrashkin et al., 2006; Oesterle and Campbell, 2009; Taylor et al., 2012), making it difficult to test the consequences of their absence on $\mathrm{HC}$ survival and hearing. 

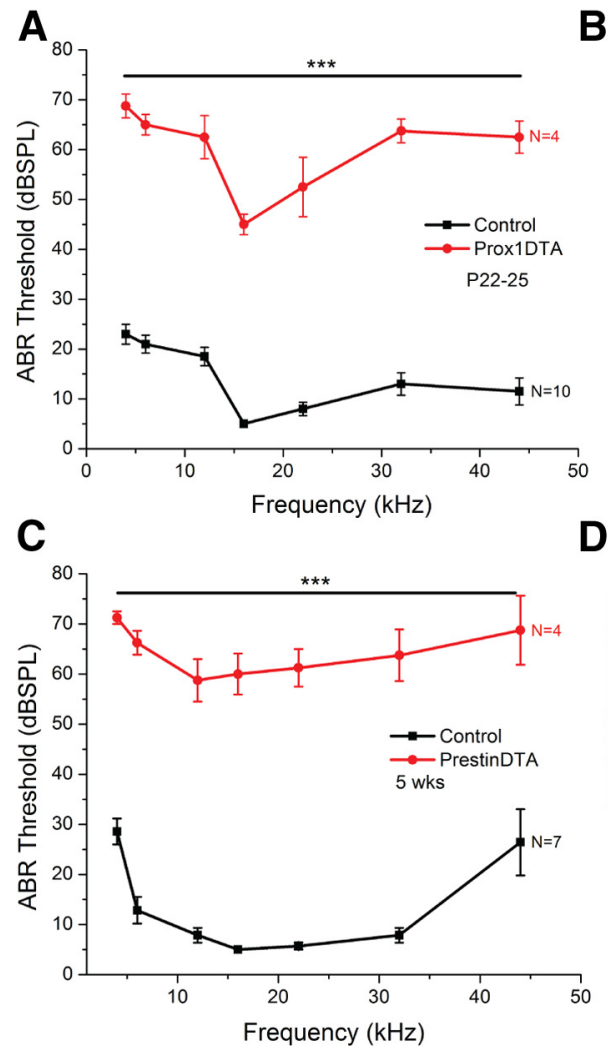

Figure 8. Increased ABR thresholds in Prox1DTA mice correlates with outer HC loss and absence of cochlear amplification. $A, B$, ABR (wave I) thresholds at frequencies $4-44 \mathrm{kHz}$ of Prox1DTA and control littermate mice at P22-P25 (A) and at 5- 6 weeks (wks) of age $(\boldsymbol{B})$. Data are expressed as mean \pm SEM. Thresholds are statistically different $(40-50 \mathrm{~dB})$ at all frequencies analyzed between Prox1DTA and control mice as determined by a two-way ANOVA followed by Student's $t$ test with Bonferroni correction, $\left.{ }^{* * *} p<0,001\right)$. $N$ values are shown on the side of each graph. $C$, ABR thresholds of 5-week-old PrestinDTA mice (where specific ablation of outer HCs was induced by tamoxifen injection at P21-P22). Statistically significant increase in thresholds $(\sim 50 \mathrm{~dB})$ are seen in PrestinDTA mice relative to control littermates as determined by a two-way ANOVA followed by Student's $t$ test with Bonferroni correction, ${ }^{* * *} p<0,001$. There are no significant differences in ABR thresholds between PrestinDTA and Prox1DTA mice (two-way ANOVA followed by Bonferroni correction, $p>0.05$ ). $\boldsymbol{D}$, Representative optical slices of apical cochlea of PrestinDTA and control littermate mice at 5 weeks of age showing considerable loss of outer $\mathrm{HCS}(\mathrm{OHC})$ in the mutant mice. IHC, inner $\mathrm{HC}$. Scale bars, $10 \mu \mathrm{m}$.

Here we achieved cochlear SC-specific ablation using Cremediated DTA expression, which produces cell-autonomous death via apoptosis due to disruption of protein synthesis and actin polymerization (Kochi and Collier, 1993; Collier, 2001; Bektaş et al., 2009). This approach has been effectively used in retina, heart, dorsal root ganglia, and utricle (Ivanova et al., 2005; Chen and Nathans, 2007; Abrahamsen et al., 2008; Burns et al., 2012) to dissect the roles of specific cell types.

In the neonatal organ of Corti, we showed that after 1 week of significant PC and DC loss, outer HCs survive and stay attached to the reticular lamina. However, their organization, as well as development of their neural innervation, is severely affected during this time. Two weeks after SC death onset, accumulated PC and DC loss and disruption of their phalanges trigger outer $\mathrm{HC}$ degeneration, in part due to breakdown of cochlear microarchitecture. In contrast, inner HC survival is independent of substantial loss of PCs and DCs.

Prox1DTA mice are the first model of specific SC ablation in the cochlea and serve as reporters of Cre activity. At P4-P8, more PCs and DCs died in Prox1DTA cochleae than those EYFP+ cells in Prox1EYFP cochleae (Yu et al., 2010) but fewer than those Tomato + cells in Prox1Ai14 cochleae. The Rosa26 ${ }^{\text {DTA }}$ allele seems to be a Cre-reporter with intermediate efficiency between Rosa26 ${ }^{\mathrm{EYFP}}$ and Ai14.

\section{PCs/DCs and organ of Corti physical integrity}

In Prox1DTA mice, loss of DCs and outer PCs starts at P2-P4 while loss of outer HCs becomes significant between $\mathrm{P} 8$ and P14, the time of onset of electromotility and hearing in mice (Abe et al., 2007). PCs and DCs are the physical connection between HCs and the basilar membrane (Parsa et al., 2012) and have stiff cell bodies formed by bundles of microtubules and actin filaments (Tucker et al., 1992; Tolomeo et al., 1996; Tolomeo and Holley, 1997). It is possible that lack of support by PCs and DCs to the newly motile outer HCs severely affects their survival. Additionally, at $\sim \mathrm{P} 8-\mathrm{P} 14$, key changes occur to the SCs that are required for hearing function. For example, PCs and DCs acquire slimmer columnar shapes and open the fluid-filled tunnel of Corti and the spaces of Nuel around the outer HCs (Colvin et al., 1996; Souter et al., 1997; Vater et al., 1997; Shim et al., 2005; Inoshita et al., 2008). A previous model that supports relevance of DC-outer HC connections is the prestin chimera mouse where DCs underneath the short, prestinnegative outer HCs elongate to maintain the link to the basilar membrane, likely as a compensatory mechanism (Cheatham et al., 2009).

Additionally, we showed that absence of outer PC and DC phalanges affects HC/SC alternation (Togashi et al., 2011) and hair-bundle orientation. Radial orientation of the hair bundles is very important for effective mechanoelectrical transduction (Schwander et al., 2010) and is established at birth even though HCs continue developing for 2-3 weeks (Kelly and Chen, 2007, 2009). Misoriented hair bundles appear in Prox1DTA cochleae associated with missing SC phalanges around $\mathrm{HCs}$ and seem to be a result of $\mathrm{HC}$ body rotation. These results reveal SC relevance in maintaining organ of Corti radial organization.

A remarkable finding in Prox1DTA mice is that, in contrast to previous ideas, sealing of the reticular lamina effectively occurs despite significant loss of PCs and DCs. Cochlear SCs, similar to glial cells in the CNS (Schachtrup et al., 2011; Peng and Carbonetto, 2012), contribute to scar formation after injury. In the case of SCs, this occurs by modifications in their contacts at the reticular lamina to keep it sealed (Forge, 1985; Raphael and Altschuler, 1991a, b; Raphael, 1993; Leonova and Raphael, 1997). In Prox1DTA mice, we demonstrated that PCs and DCs may be spared for this function and Hensen cells can take over most of the role in scar formation, migrating into the $\mathrm{HC}$ region. Similar migration occurs after drug damage in wild-type mice (Taylor et al., 2012).

\section{PCs/DCs and cochlear homeostasis}

Some data suggest that PCs and DCs contribute to cochlear uptake mechanisms during hearing. Excess glutamate released at HC synapses causes outer HC degeneration, while DCs express 
the glutamate/aspartate transporter, a glutamate uptake mechanism (Furness et al., 2002; Lu et al., 2010). $\mathrm{K}^{+}$, on the other hand, is the main charge moving through $\mathrm{HC}$ mechanoelectrical transduction channels and is released by outer HCs via KCNQ4 channels (Kubisch et al., 1999). DCs around them express Kir4.1, a K ${ }^{+}$ channel subunit that when missing produces outer HC loss between P6 and P18 in mice (Rozengurt et al., 2003), and Kcc4, a $\mathrm{K}-\mathrm{Cl}$ cotransporter whose absence causes severe HC loss and hearing impairment (Boettger et al., 2002). Thus, reduced glutamate and $\mathrm{K}^{+}$uptake after significant DC loss might contribute to outer HC loss around hearing onset in Prox1DTA mice. SCs seem to be as important for maintaining $\mathrm{HC}$ homeostasis as glial cells are to neurons in the retina and the CNS (Miguel-Hidalgo, 2009; Eulenburg and Gomeza, 2010; Zhao and Rempe, 2010; Bringmann and Wiedemann, 2012).

Additionally, gap-junction networks between SCs are key to hearing. Mutations in the gap-junction protein connexin26 (Cx26), present in SCs, account for approximately half of the cases of nonsyndromic hearing loss in humans (Mahboubi et al., 2012). In Prox1DTA mice, the connexin network is likely affected by a reduced number of PCs and DCs; however, the effects observed are spatially restricted and less severe than those seen after specific deletion of Cx26 in SCs. Conditional deletion of Cx26 at approximately embryonic day 10 caused SC death around the inner HCs at hearing onset, followed by substantial loss of HCs, PCs, and DCs (Cohen-Salmon et al., 2002). In this model, cell death was worsened by breakdown of the reticular lamina and massive $\mathrm{K}^{+}$influx into the organ. Conditional deletion of Cx26 in SCs at embryonic day 19 produced loss of outer HCs and DCs at hearing onset, also likely associated with reticular lamina disruption (Sun et al., 2009). In Prox1DTA mice, preservation of the connexin network around inner HCs may contribute to their survival.

\section{HC innervation after PC/DC loss}

It is thought that neurotrophins released by HCs and SCs are important for the correct patterning of neuronal terminals and synapse formation during development (Knipper et al., 1996; Puligilla et al., 2007). Indeed, we demonstrated that loss of PCs and DCs substantially affects development of neuronal innervation to the outer HCs in Prox1DTA mice, likely by deficits in glutamate buffering and neurotrophic support. At P8, before $\mathrm{HC}$ loss is significant, the innervation pattern to the outer $\mathrm{HC}$ area in Prox1DTA mice is abnormal and by P14 lack of refinement is evident. Additionally, swelling of the terminals at P14 is similar to the signs of neuronal damage seen after noise exposure, which has been correlated with excitotoxicity by glutamate accumulation after HC and SC loss (Gil-Loyzaga and Pujol, 1990; Pujol and Puel, 1999; Kujawa and Liberman, 2009).

\section{Impact of PC/DC loss on hearing}

In Prox1DTA mice, ABR waves are elicited only at high soundpressure levels. ABR threshold elevation of $40-50 \mathrm{~dB}$ is consistent with previous reports in models lacking cochlear amplification (Liberman et al., 2002; Cheatham et al., 2009). We demonstrate that similar threshold shifts are seen in PrestinDTA mice 2 weeks after specific outer $\mathrm{HC}$ ablation. The major contributor to severe hearing impairment in Prox1DTA mice seems to be the absence of the amplifier outer HCs.

Remarkably, we demonstrated that outer PCs, DCs, and outer HCs are not essential to survival of spiral ganglion neurons at least up to 6 weeks of age in mice. These results are in contrast to previous ideas about trophic support from the organ of Corti to the primary auditory neurons and points to relevant autocrine and paracrine survival loops existing within the ganglion. However, we cannot rule out in Prox1DTA mice that preservation of inner PCs, inner HCs, and inner phalangeal cells may contribute to neuronal survival (Stankovic et al., 2004; Sugawara et al., 2005; Teufert et al., 2006; Zilberstein et al., 2012). Our data suggest that cochlear implants may successfully stimulate neurons in cochleae with few PCs, DCs, and outer HCs.

In conclusion, we demonstrated that PCs and DCs are necessary for outer HC survival and development of neural connections. We also demonstrated that reticular lamina sealing, inner $\mathrm{HC}$ and spiral neuron survival are independent of PC and DC absence and the disruption this created in the organ of Corti. Our data show that effective strategies to regenerate hearing in mammals require not only replenishing lost $\mathrm{HCs}$ but also repopulating specific SC pools that provide structural and trophic support to the organ of Corti.

\section{References}

Abe T, Kakehata S, Kitani R, Maruya S, Navaratnam D, Santos-Sacchi J, Shinkawa H (2007) Developmental expression of the outer hair cell motor prestin in the mouse. J Membr Biol 215:49-56. CrossRef Medline

Abrahamsen B, Zhao J, Asante CO, Cendan CM, Marsh S, Martinez-Barbera JP, Nassar MA, Dickenson AH, Wood JN (2008) The cell and molecular basis of mechanical, cold, and inflammatory pain. Science 321:702-705. CrossRef Medline

Abrashkin KA, Izumikawa M, Miyazawa T, Wang CH, Crumling MA, Swiderski DL, Beyer LA, Gong TW, Raphael Y (2006) The fate of outer hair cells after acoustic or ototoxic insults. Hear Res 218:20-29. CrossRef Medline

Ahmad M, Bohne BA, Harding GW (2003) An in vivo tracer study of noiseinduced damage to the reticular lamina. Hear Res 175:82-100. CrossRef Medline

Barclay M, Ryan AF, Housley GD (2011) Type I vs type II spiral ganglion neurons exhibit differential survival and neuritogenesis during cochlear development. Neural Dev 6:33. CrossRef Medline

Bektaş M, Varol B, Nurten R, Bermek E (2009) Interaction of diphtheria toxin (fragment A) with actin. Cell Biochem Funct 27:430-439. CrossRef Medline

Bermingham-McDonogh O, Oesterle EC, Stone JS, Hume CR, Huynh HM, Hayashi T (2006) Expression of Proxl during mouse cochlear development. J Comp Neurol 496:172-186. CrossRef Medline

Bird JE, Daudet N, Warchol ME, Gale JE (2010) Supporting cells eliminate dying sensory hair cells to maintain epithelial integrity in the avian inner ear. J Neurosci 30:12545-12556. CrossRef Medline

Boettger T, Hübner CA, Maier H, Rust MB, Beck FX, Jentsch TJ (2002) Deafness and renal tubular acidosis in mice lacking the $\mathrm{K}-\mathrm{Cl}$ cotransporter Kcc4. Nature 416:874-878. CrossRef Medline

Bringmann A, Wiedemann P (2012) Müller glial cells in retinal disease. Ophthalmologica 227:1-19. CrossRef Medline

Brownell WE (1990) Outer hair cell electromotility and otoacoustic emissions. Ear Hear 11:82-92. CrossRef Medline

Burns JC, Cox BC, Thiede BR, Zuo J, Corwin JT (2012) In vivo proliferative regeneration of balance hair cells in newborn mice. J Neurosci 32:65706577. CrossRef Medline

Cheatham MA, Low-Zeddies S, Naik K, Edge R, Zheng J, Anderson CT, Dallos P (2009) A chimera analysis of prestin knock-out mice. J Neurosci 29:12000-12008. CrossRef Medline

Chen J, Nathans J (2007) Genetic ablation of cone photoreceptors eliminates retinal folds in the retinal degeneration 7 (rd7) mouse. Invest Ophthalmol Vis Sci 48:2799-2805. CrossRef Medline

Cohen-Salmon M, Ott T, Michel V, Hardelin JP, Perfettini I, Eybalin M, Wu T, Marcus DC, Wangemann P, Willecke K, Petit C (2002) Targeted ablation of connexin26 in the inner ear epithelial gap junction network causes hearing impairment and cell death. Curr Biol 12:1106-1111. CrossRef Medline

Collier RJ (2001) Understanding the mode of action of diphtheria toxin: a perspective on progress during the 20th century. Toxicon 39:1793-1803. CrossRef Medline

Colvin JS, Bohne BA, Harding GW, McEwen DG, Ornitz DM (1996) Skel- 
etal overgrowth and deafness in mice lacking fibroblast growth factor receptor 3. Nat Genet 12:390-397. CrossRef Medline

Corwin JT, Cotanche DA (1988) Regeneration of sensory hair cells after acoustic trauma. Science 240:1772-1774. CrossRef Medline

Cox BCL, Z; Mellado Lagarde, M. M.; Zuo, J. (2012) Conditional gene expression in the mouse inner ear using Cre-loxP. J Assoc Res Otalaryagol 13:295-322. CrossRef Medline

Davies S, Forge A (1987) Preparation of the mammalian organ of Corti for scanning electron microscopy. J Microsc 147:89-101. CrossRef Medline

Eulenburg V, Gomeza J (2010) Neurotransmitter transporters expressed in glial cells as regulators of synapse function. Brain Res Rev 63:103-112. CrossRef Medline

Fang J, Zhang WC, Yamashita T, Gao J, Zhu MS, Zuo J (2012) Outer hair cell-specific prestin-CreER(T2) knockin mouse lines. Genesis 50: 124-131. CrossRef Medline

Forge A (1985) Outer hair cell loss and supporting cell expansion following chronic gentamicin treatment. Hear Res 19:171-182. CrossRef Medline

Forge A, Li L, Nevill G (1998) Hair cell recovery in the vestibular sensory epithelia of mature guinea pigs. J Comp Neurol 397:69-88. CrossRef Medline

Furness DN, Hulme JA, Lawton DM, Hackney CM (2002) Distribution of the glutamate/aspartate transporter GLAST in relation to the afferent synapses of outer hair cells in the guinea pig cochlea. J Assoc Res Otolaryngol 3:234-247. CrossRef Medline

Geisler CD, Sang C (1995) A cochlear model using feed-forward outer-haircell forces. Hear Res 86:132-146. CrossRef Medline

Gilbert WV (2010) Alternative ways to think about cellular internal ribosome entry. J Biol Chem 285:29033-29038. CrossRef Medline

Gil-Loyzaga P, Pujol R (1990) Neurotoxicity of kainic acid in the rat cochlea during early developmental stages. Eur Arch Otorhinolaryngol 248:40-48. CrossRef Medline

He DZ, Evans BN, Dallos P (1994) First appearance and development of electromotility in neonatal gerbil outer hair cells. Hear Res 78:77-90. CrossRef Medline

Hibino H, Kurachi Y (2006) Molecular and physiological bases of the $\mathrm{K}+$ circulation in the mammalian inner ear. Physiology (Bethesda) 21:336-345. CrossRef Medline

Inoshita A, Iizuka T, Okamura HO, Minekawa A, Kojima K, Furukawa M, Kusunoki T, Ikeda K (2008) Postnatal development of the organ of Corti in dominant-negative Gjb2 transgenic mice. Neuroscience 156: 1039-1047. CrossRef Medline

Ivanova A, Signore M, Caro N, Greene ND, Copp AJ, Martinez-Barbera JP (2005) In vivo genetic ablation by Cre-mediated expression of diphtheria toxin fragment A. Genesis 43:129-135. CrossRef Medline

Kelly M, Chen P (2007) Shaping the mammalian auditory sensory organ by the planar cell polarity pathway. Int J Dev Biol 51:535-547. CrossRef Medline

Kelly MC, Chen P (2009) Development of form and function in the mammalian cochlea. Curr Opin Neurobiol 19:395-401. CrossRef Medline

Knipper M, Zimmermann U, Rohbock K, Köpschall I, Zenner HP (1996) Expression of neurotrophin receptor trkB in rat cochlear hair cells at time of rearrangement of innervation. Cell Tissue Res 283:339-353. CrossRef Medline

Knipper M, Köpschall I, Rohbock K, Köpke AK, Bonk I, Zimmermann U, Zenner H (1997) Transient expression of NMDA receptors during rearrangement of AMPA-receptor-expressing fibers in the developing inner ear. Cell Tissue Res 287:23-41. Medline

Kochi SK, Collier RJ (1993) DNA fragmentation and cytolysis in U937 cells treated with diphtheria toxin or other inhibitors of protein synthesis. Exp Cell Res 208:296-302. CrossRef Medline

Kubisch C, Schroeder BC, Friedrich T, Lütjohann B, El-Amraoui A, Marlin S, Petit C, Jentsch TJ (1999) KCNQ4, a novel potassium channel expressed in sensory outer hair cells, is mutated in dominant deafness. Cell 96:437446. CrossRef Medline

Kujawa SG, Liberman MC (2009) Adding insult to injury: cochlear nerve degeneration after "temporary" noise-induced hearing loss. J Neurosci 29:14077-14085. CrossRef Medline

Lallemend F, Vandenbosch R, Hadjab S, Bodson M, Breuskin I, Moonen G, Lefebvre PP, Malgrange B (2007) New insights into peripherin expression in cochlear neurons. Neuroscience 150:212-222. CrossRef Medline

Lavigne-Rebillard M, Pujol R (1990) Auditory hair cells in human fetuses: synaptogenesis and ciliogenesis. J Electron Microsc Tech 15:115-122. CrossRef Medline

Leonova EV, Raphael Y (1997) Organization of cell junctions and cytoskeleton in the reticular lamina in normal and ototoxically damaged organ of Corti. Hear Res 113:14-28. CrossRef Medline

Liberman MC, Gao J, He DZ, Wu X, Jia S, Zuo J (2002) Prestin is required for electromotility of the outer hair cell and for the cochlear amplifier. Nature 419:300-304. CrossRef Medline

Lu H, Wang X, Sun W, Hu Y, Gong S (2010) New insights into glutamate ototoxicity in cochlear hair cells and spiral ganglion neurons. Acta Otolaryngol 130:1316-1323. CrossRef Medline

Madisen L, Zwingman TA, Sunkin SM, Oh SW, Zariwala HA, Gu H, Ng LL, Palmiter RD, Hawrylycz MJ, Jones AR, Lein ES, Zeng H (2010) A robust and high-throughput Cre reporting and characterization system for the whole mouse brain. Nat Neurosci 13:133-140. CrossRef Medline

Mahboubi H, Dwabe S, Fradkin M, Kimonis V, Djalilian HR (2012) Genetics of hearing loss: where are we standing now? Eur Arch Otorhinolaryngol 269:1733-1745. CrossRef Medline

McDowell B, Davies S, Forge A (1989) The effect of gentamicin-induced hair cell loss on the tight junctions of the reticular lamina. Hear Res 40:221-232. CrossRef Medline

Miguel-Hidalgo JJ (2009) The role of glial cells in drug abuse. Curr Drug Abuse Rev 2:76-82. CrossRef Medline

Oesterle EC, Campbell S (2009) Supporting cell characteristics in longdeafened aged mouse ears. J Assoc Res Otolaryngol 10:525-544. CrossRef Medline

Parsa A, Webster P, Kalinec F (2012) Deiters cells tread a narrow path-the Deiters cells-basilar membrane junction. Hear Res 290:13-20. CrossRef Medline

Peng H, Carbonetto S (2012) Astrocyte polarization and wound healing in culture: studying cell adhesion molecules. Methods Mol Biol 814: 177-188. CrossRef Medline

Pujol R, Puel JL (1999) Excitotoxicity, synaptic repair, and functional recovery in the mammalian cochlea: a review of recent findings. Ann N Y Acad Sci 884:249-254. CrossRef Medline

Puligilla C, Feng F, Ishikawa K, Bertuzzi S, Dabdoub A, Griffith AJ, Fritzsch B, Kelley MW (2007) Disruption of fibroblast growth factor receptor 3 signaling results in defects in cellular differentiation, neuronal patterning, and hearing impairment. Dev Dyn 236:1905-1917. CrossRef Medline

Raphael Y (1993) Reorganization of the chick basilar papilla after acoustic trauma. J Comp Neurol 330:521-532. CrossRef Medline

Raphael Y (2002) Cochlear pathology, sensory cell death and regeneration. Br Med Bull 63:25-38. CrossRef Medline

Raphael Y, Altschuler RA (1991a) Reorganization of cytoskeletal and junctional proteins during cochlear hair cell degeneration. Cell Motil Cytoskeleton 18:215-227. CrossRef Medline

Raphael Y, Altschuler RA (1991b) Scar formation after drug-induced cochlear insult. Hear Res 51:173-183. CrossRef Medline

Raphael Y, Altschuler RA (1992) Early microfilament reorganization in injured auditory epithelia. Exp Neurol 115:32-36. CrossRef Medline

Rozengurt N, Lopez I, Chiu CS, Kofuji P, Lester HA, Neusch C (2003) Time course of inner ear degeneration and deafness in mice lacking the Kir4.1 potassium channel subunit. Hear Res 177:71-80. CrossRef Medline

Russell IJ, Nilsen KE (1997) The location of the cochlear amplifier: spatial representation of a single tone on the guinea pig basilar membrane. Proc Natl Acad Sci U S A 94:2660-2664. CrossRef Medline

Ryals BM, Rubel EW (1988) Hair cell regeneration after acoustic trauma in adult Coturnix quail. Science 240:1774-1776. CrossRef Medline

Schachtrup C, Le Moan N, Passino MA, Akassoglou K (2011) Hepatic stellate cells and astrocytes: stars of scar formation and tissue repair. Cell Cycle 10:1764-1771. CrossRef Medline

Schwander M, Kachar B, Müller U (2010) Review series: the cell biology of hearing. J Cell Biol 190:9-20. CrossRef Medline

Serra A, La Mantia I (1982) Ultrastructural changes in the cochlear sensory epithelium following damage to the organ of Corti. Arch Otorhinolaryngol 234:163-166. CrossRef Medline

Shim K, Minowada G, Coling DE, Martin GR (2005) Sprouty2, a mouse deafness gene, regulates cell fate decisions in the auditory sensory epithelium by antagonizing FGF signaling. Dev Cell 8:553-564. CrossRef Medline

Sobkowicz HM, August BK, Slapnick SM (2002) Influence of neurotrophins on the synaptogenesis of inner hair cells in the deaf Bronx waltzer 
(bv) mouse organ of Corti in culture. Int J Dev Neurosci 20:537-554. CrossRef Medline

Souter M, Nevill G, Forge A (1997) Postnatal maturation of the organ of Corti in gerbils: morphology and physiological responses. J Comp Neurol 386:635-651. CrossRef Medline

Srinivasan RS, Dillard ME, Lagutin OV, Lin FJ, Tsai S, Tsai MJ, Samokhvalov IM, Oliver G (2007) Lineage tracing demonstrates the venous origin of the mammalian lymphatic vasculature. Genes Dev 21:2422-2432. CrossRef Medline

Stankovic K, Rio C, Xia A, Sugawara M, Adams JC, Liberman MC, Corfas G (2004) Survival of adult spiral ganglion neurons requires erbB receptor signaling in the inner ear. J Neurosci 24:8651-8661. CrossRef Medline

Sugawara M, Corfas G, Liberman MC (2005) Influence of supporting cells on neuronal degeneration after hair cell loss. J Assoc Res Otolaryngol 6:136-147. CrossRef Medline

Sun Y, Tang W, Chang Q, Wang Y, Kong W, Lin X (2009) Connexin30 null and conditional connexin 26 null mice display distinct pattern and time course of cellular degeneration in the cochlea. J Comp Neurol 516:569579. CrossRef Medline

Taylor RR, Jagger DJ, Forge A (2012) Defining the cellular environment in the organ of Corti following extensive hair cell loss: a basis for future sensory cell replacement in the cochlea. PLoS One 7:e30577. CrossRef Medline

Teufert KB, Linthicum FH Jr, Connell SS (2006) The effect of organ of Corti loss on ganglion cell survival in humans. Otol Neurotol 27:1146-1151. CrossRef Medline

Togashi H, Kominami K, Waseda M, Komura H, Miyoshi J, Takeichi M,
Takai Y (2011) Nectins establish a checkerboard-like cellular pattern in the auditory epithelium. Science 333:1144-1147. CrossRef Medline

Tolomeo JA, Holley MC (1997) Mechanics of microtubule bundles in pillar cells from the inner ear. Biophys J 73:2241-2247. CrossRef Medline

Tolomeo JA, Steele CR, Holley MC (1996) Mechanical properties of the lateral cortex of mammalian auditory outer hair cells. Biophys J 71: 421-429. CrossRef Medline

Tucker JB, Paton CC, Richardson GP, Mogensen MM, Russell IJ (1992) A cell surface-associated centrosomal layer of microtubule-organizing material in the inner pillar cell of the mouse cochlea. J Cell Sci 102: 215-226. Medline

Vater M, Lenoir M, Pujol R (1997) Development of the organ of Corti in horseshoe bats: scanning and transmission electron microscopy. J Comp Neurol 377:520-534. CrossRef Medline

Von Bekesy G (1952) Resting potentials inside the cochlear partition of the guinea pig. Nature 169:241-242. CrossRef Medline

Warchol ME (2011) Sensory regeneration in the vertebrate inner ear: differences at the levels of cells and species. Hear Res 273:72-79. CrossRef Medline

Yu Y, Weber T, Yamashita T, Liu Z, Valentine MB, Cox BC, Zuo J (2010) In vivo proliferation of postmitotic cochlear supporting cells by acute ablation of the retinoblastoma protein in neonatal mice. J Neurosci 30:5927-5936. CrossRef Medline

Zhao Y, Rempe DA (2010) Targeting astrocytes for stroke therapy. Neurotherapeutics 7:439-451. CrossRef Medline

Zilberstein Y, Liberman MC, Corfas G (2012) Inner hair cells are not required for survival of spiral ganglion neurons in the adult cochlea. J Neurosci 32:405-410. CrossRef Medline 